\title{
Patient Variable Biases in Clinical Judgment: Conceptual Overview and Methodological Considerations
}

\author{
Steven Regeser López \\ University of Southern California
}

\begin{abstract}
Specific conceptual factors are presented as having contributed to the negative findings of past psychotherapy bias research. Among these factors are the restrictive nature of both the definition of bias and the model of the biased clinician. A review of published studies of several patient variable biases (e.g., gender, race/ethnicity, and age) indicates that bias may best be defined in broader terms and that its occurrence may be more circumscribed than originally conceived. In addition, the lack of a theoretical perspective in this area of research is noted and the applicability of some social cognitive processes is discussed. Methodological factors are also considered, and recommendations for future research are offered.
\end{abstract}

In the 1960 s, clinical researchers began investigating the impact that patient variables such as race (Yamamoto, James, Bloombaum, \& Hattem, 1967) and social class (Haase, 1964) have on mental health professionals' clinical judgments and treatment practices. Since then, other sociodemographic variables have been studied, including gender (Smith, 1980), ethnicity (McLaughlin \& Balch, 1980), and age (Perlick \& Atkins, 1984). Both experimental and archival methods have been used in this area of research. For experimental studies, clinical stimuli, such as case summaries, audiotaped clinical interviews, or test protocols are typically presented to clinicians, who are then asked to make clinical ratings of the case or cases. The patient variable under investigation is usually manipulated so that the patient is identified as female or Black in one condition and as male or White in the other condition. For archival research, data are collected from patient files regarding amount of medication, number of sessions, diagnoses, and related variables. To determine if the patient variable under study is responsible for any differential treatment, statistical and methodological controls are sometimes applied to rule out actual differences in the level of psychopathology across the patient groups and other potential confounds. For example, if the patient's race is under investigation, steps are taken to control for the possible effects of social class and age. Considered together, this archival and experimental research has been referred to as the psychotherapy bias literature.

Within this research, the term bias usually implies a prejudgment or prejudice. In other words, it is used to refer to error or inaccuracy in clinical judgments of women, the elderly, and racial/ethnic minority group members. Gender bias, for exam-

Preparation of this manuscript was supported in part by a National Institutes of Health Biomedical Research Support Grant. I would like to express appreciation to Rena Repetti, Bernie Weiner, and Sandra Graham for their critical reading of previous drafts.

Correspondence concerning this article should be addressed to Steven Regeser López, Department of Psychology, Seeley G. Mudd Building, University of Southern California, University Park, Los Angeles, California 90089 . ple, is reported in analogue studies when a woman patient is judged to be significantly more disturbed than a male patient with the identical presenting problem (e.g., S. I. Abramowitz, Abramowitz, Jackson, \& Gomes, 1973). Similarly, in clinical studies, bias is identified when treatment differences are found between male and female patients when the level of psychopathology has been shown to be equivalent for both groups (e.g., Stein, Del Gaudio, \& Ansley, 1976), or when the level of psychopathology is statistically controlled (S. I. Abramowitz \& Herrera, 1981; Rosenfield, 1982). Both research designs equate bias with findings that women or minority group members are perceived as more disturbed or as requiring more treatment. This has been referred to as the overpathologizing bias (López, 1983b). A major assumption underlying this bias is that these differences are not due to actual differences between genders, age groups, or racial/ethnic groups but to error on the part of practitioners.

Reviews of the psychotherapy bias literature conclude that there is little evidence of bias (S. I. Abramowitz \& Murray, 1983; Davidson \& Abramowitz, 1980; Smith, 1980). According to the reviewers, patient variables such as gender and race have not been found to have an effect on clinicians' judgments or on the type of treatment provided. The only patient variable effect that has been reported to have consistent empirical support is social class: Lower social class patients have been judged to be more seriously disturbed than middle and higher social class patients, even though no differences were found in the presenting problems (C. V. Abramowitz \& Dokecki, 1977). Some observers have attributed the overall negative findings of bias to the alleged social desirability of the analogue methodology, which has served as the primary research method (S. I. Abramowitz \& Herrera, 1981; Hare-Mustin, 1983). As a result, some investigators have called for a moratorium on analogue research (S. I. Abramowitz \& Murray, 1983; Davidson \& Abramowitz, 1980), arguing that contextual studies, such as archival studies, should be used in lieu of experimentally based methods.

Although it is important to consider methodological factors that may be contributing to investigators' inability to uncover 
possible biases, it may be even more important at this time to consider conceptual factors. The purpose of this article is to reevaluate the clinical bias literature by focusing on conceptual notions that have guided much of this research, specifically the definition of bias and the model of the biased clinician. On the basis of a comprehensive review of this research, I argue that the past definition of psychotherapy bias and the model of the biased clinician may have been too restrictive, making it difficult to identify bias. To address this problem, I recommend that future investigators adopt a broader definition of bias and give more attention to the specific symptoms and disorders most likely to result in biased judgments. I also point out the lack of a theoretical framework in past research, and I review the available data to support a social cognitive perspective of patient variable biases in clinical judgment. Accordingly, I examine the applicability of attributions, base rates, hypothesis testing, and memory to this area of research. This theoretical perspective was chosen because it integrates the study of judgment and decision making with the social psychological study of stereotyping and prejudice. Last, I discuss methodological factors related to these conceptual issues, with particular attention to the role of analogue methods in the study of patient variable biases.

This review differs from most other reviews in clinical bias in two important ways. First, all significant patient variables that have been studied in this area are examined. The most frequently studied variables (gender, race, ethnicity, and social class) are reviewed, as well as age, mental retardation, religious background, and weight-four patient variables that have recently received attention. The inclusion of studies pertaining to all such variables may begin to point out consistencies and inconsistencies in the clinical judgment of several patient groups.

The second difference between this and other reviews is that this review focuses more on therapists' judgments than on therapists' behavior. Although studies of actual clinical behavior are considered, such as drugs prescribed and number of therapy sessions, greater emphasis is placed on studies of clinicians' judgments (i.e., the perceptions of the disorder's severity and the patient's prognosis, diagnosis, and need for treatment). This focus was chosen because the study of clinical judgment is most conducive to the use of experimental methods. In accordance with Smith's (1980) observation, the effect of the patient variable on clinical judgment can only be identified via experimental studies. The ex post facto designs used in "naturalistic" studies are limited in identifying patient variable effects. Even with the use of controls, there still may exist other variables that account for differential judgment or treatment. A second reason for the focus on clinical judgment is that it is more limited in scope than psychotherapy. Therefore, the conceptualization of possible biases in clinical judgment is more manageable than the conceptualization of possible biases in the entire psychotherapy process, from initial evaluation to outcome. Even though treatment outcome is ultimately the most important dependent measure in the study of psychotherapy bias, beginning efforts in conceptualizing bias will be better served by addressing a more focused and perhaps more manageable area such as clinical judgment.

Several criteria were adhered to in selecting the studies for review. The most important criterion was that the patient variable under investigation was likely to be responsible for apparent biases in judgment. Three research designs fit this criterion. The first and most obvious type is the experimental study of clinical judgment in which the patient variable is manipulated (e.g., Perlick \& Atkins, 1984). When one uses this analogue method, the patient descriptor being studied is clearly implicated in any differential judgments. In the second research approach, bias is assessed by reviewing patient records to determine if different patient groups receive different levels of treatment. To ensure that observed group differences in treatment reflect therapists' biases and not true differences in the status of the patient groups, investigators use statistical and methodological controls (e.g., Stein et al., 1976). Treatment-based studies that do not control for these possible group differences were not included (e.g., Kirshner \& Johnston, 1983; Popkin, Mackenzie, $\&$ Callies, 1984). The third group of studies included here compares diagnoses derived from usual clinical procedures with diagnoses derived from standardized clinical interviews (e.g., Simon, Fleiss, Gurland, Stiller, \& Sharpe, 1973) or from close adherence to diagnostic criteria (Mukherjee, Shukla, Woodle, Rosen, \& Olarte, 1983). It is assumed that diagnoses associated with standardized clinical interviews or with close adherence to diagnostic criteria are more accurate than diagnoses derived by facilities' usual (and oftentimes less thorough) evaluation procedures. Because the latter two research methods are based on clinicians' judgments of their clinical cases, they are jointly referred to as the clinical method, whereas the experimental approach is referred to as the analogue method.

The second criterion used in selecting studies for this review concerns the dependent variable under investigation; only those studies that examined judgments of a clinical nature are included. Evaluations of problem, symptom, or disorder severity, as well as diagnosis, represent such judgments. The primary reason for choosing these dependent variables is that they are central to evaluations of psychopathology as evidenced by their implications for treatment. It should be noted that with the review's focus on judgments, studies reporting treatment differentials are assumed to reflect judgment differences. The prescription of relatively more medication for one patient group, for example, is thought to represent judgments of relatively more disturbance for that patient group.

In addition to the above criteria, studies were not included in this review if they (a) summarized findings without reporting data (e.g., Haase, 1964), (b) reported summary scores for a number of variables including nonclinical judgments (e.g., Merluzzi \& Merluzzi, 1978), (c) reported symptom scores of patient groups without relating them to independent clinical judgments or treatment practices (e.g., Derogatis, Covi, Lipman, Davis, \& Rickels, 1971), or (d) used judges who were not mental health professionals or trainees, such as health personnel (B. Bernstein \& Kane, 1981; Biener, 1983) and college students (Coie, Pennington, \& Buckley, 1974; Norman \& Martinez, 1978). In short, the studies included here examined the influence of salient patient variables on practitioners' and trainees' specific clinical judgments and treatment practices.

\section{Definition of Bias Reconsidered}

In this section, I consider the limitations with the past definition of clinical judgment bias and propose that the definition of 
bias be expanded. I then address the complexities associated with the new definitions. To evaluate the significance of the proposed definition, I compare the proportion of bias cases identified by past investigators using the old and new definitions of bias.

\section{Broadening the Definition}

A significant limitation in the original definition of bias is that all types of judgments reflecting negatively on female or minority patients are considered equally representative of bias. For instance, clinical impressions regarding the patient's likeability and diagnosis are given equal weight in considering whether bias exists, even though they are likely to represent different constructs. Because clinical judgment variables relate differently to treatment, it may be important to separately study specific types of judgment. For example, a one-point mean difference on a nine-point likeability rating scale for a Black patient in relation to a White patient seems trivial in comparison with an overdiagnosis of schizophrenia and an underdiagnosis of bipolar disorders for Black patients. The one-point difference in likeability would probably have much less impact on treatment than would the misdiagnosis. Another reason to consider the particular kinds of judgments is that the underlying processes of judgments may differ considerably across judgment types. Predictions regarding the patient's outcome and assignments of diagnoses, for example, may reflect different cognitive processes.

Although it is important to consider the different types of judgments in defining bias, the consideration of all possible types of judgment biases would be unwieldy for investigators. Taking into account the importance of the types of clinical impressions in defining bias, without including all possible impressions, this review considers those that, as noted earlier, reflect diagnoses and perceptions of problem, symptom, or disorder severity. In addition to being particularly important aspects of clinical evaluations, these judgments are among the most frequently studied, and they represent two distinct types: classification judgments (diagnosis) and continuum judgments (symptom severity).

Of these two major types of judgments, past bias research has focused primarily on severity. Investigators in general have assumed that biased evaluations can only occur in one direction, toward the perception of greater disturbance. This assumption may have served as a barrier in finding bias in clinical judgment. In addition to overpathologizing actual symptoms, practitioners may also minimize symptoms of actual pathology; that is, they may judge actual symptoms as representing normative behavior, when in fact the symptoms represent abnormal behavior. Depressive symptomatology, for example, may be judged as normative behavior for mothers of young children (Ginsberg \& Brown, 1982), and psychotic symptomatology may be judged as more normative for mentally retarded individuals than for individuals of normal intellectual functioning (Reiss, Levitan, \& Szyszko, 1982). Borrowing from Chess, Clark, and Thomas (1953), López (1983b) referred to this type of bias as the minimizing bias. Few clinical investigators have acknowledged this bias in clinical judgment. In fact, evidence in support of the minimizing bias is sometimes interpreted as pro-Black or pro-woman findings and is not interpreted as possible error.

Considering diagnostic judgments, two other potential errors can occur: overdiagnosis and underdiagnosis. In past reviews, the overdiagnostic bias was largely subsumed under the overpathologizing bias; little attention was given to the specific diagnostic entity that may have led to the perception of greater pathology. The overdiagnostic bias pays greater attention to diagnostic entities because it refers to clinicians judging one diagnosis as more appropriate as a function of the patient's gender, race, or age. Blake (1973), for example, found that clinical raters more often ascribed a schizophrenia type of diagnosis to a case summary identified as a Black patient than to an identical case summary identified as a White patient. In contrast to the overdiagnostic bias, the underdiagnostic bias occurs when a diagnostic category is judged less likely to occur in particular groups. For instance, Trachtman (1971) found that the lower social class patient was less frequently rated as having a neurotic disorder than was the middle-class patient. In summary, this review focuses on judgments of severity and diagnosis and considers evidence of both overascribing and underascribing dysfunction to a patient group.

\section{Complexities in New Definitions of Bias}

The broadening of the definition of bias is not without its limitations. The most important problem pertains to the directionality of the biased judgment. When considering only the overpathologizing bias, it seemed clear that judgments of more pathology for the female patient than for the male patient reflected a bias directed against the female patient. By also taking into consideration a minimizing bias, the directionality of the bias becomes less clear. Findings that the female patient, for example, is judged to be less disturbed than the male patient (the minimizing bias) can also be interpreted as an overpathologizing bias against the male patient; that is, more pathology is attributed to him than actually exists. It is also possible that the error in judgment is directed at both male and female patients. Stereotype research indicates that there are mirror-image stereotypes, that is, stereotypic notions directed at two groups simultaneously (Martin, 1987; McCauley, Stitt, \& Segal, 1980). Accordingly, one could argue that evidence of a given bias reflects possible error in evaluations of patients from both genders. In the example of the minimizing bias, clinicians may have dismissed the woman's presenting problems as more normative than they actually were and concurrently judged the same problems for the man as representing more pathology than actually existed.

In conducting this review, I adhered to two guidelines in addressing this problem. Whenever possible, I identified the biased judgment as that which deviated from the "true" or correct judgment. For example, in the study of race bias in the diagnosis of alcoholism (Luepnitz, Randolph, \& Gutsch, 1982), it was clear that the patient merited such a diagnosis. Therefore, because the Black patient was more often diagnosed as having a substance abuse disorder than the White patient, this finding reflected an underdiagnostic bias against the White patient, not an overdiagnostic bias against the Black patient. The Black patient was correctly diagnosed more frequently. However, only a 
few studies of diagnostic judgments provide a clear standard reflecting the true diagnosis. Therefore, in identifying the direction of bias for most studies, I assumed that the bias was directed against the patient from groups that historically have been the recipients of societal prejudices: women, Blacks, the elderly, and lower social class members. Accordingly, differences in judgments of male and female patients, for example, were judged to reflect biases against the female patient. This assumption is less than ideal. But until more studies incorporate a clear standard by which to compare the obtained judgments, this assumption may be the best available alternative in dealing with the complex issue of directionality.

A second problem in broadening the definition of bias is the apparent lack of independence between judgments of severity and diagnosis. Judgments of symptom severity are likely to influence judgments of diagnosis, and vice versa. Therefore, one could argue that the distinction between biases of diagnostic judgments and biases of severity judgments is more of an artifact than a true distinction of the types of bias. Evidence for this position can be found in the studies of a mental retardation bias conducted by Reiss and his associates; each of the studies found support for the minimizing bias and for the underdiagnostic bias (Reiss et al., 1982; Reiss \& Szyszko, 1983), suggesting that the two types of bias are very much related.

The rationale for the separation of diagnosis and symptom severity judgments is more conceptual than empirical in nature. Judgments of severity are likely to be conceptually distinct from judgments of diagnosis, though not on all occasions. Support for this distinction is particularly evident in the Perlick and Atkins (1984) study. The older patient and the middle-aged patient were equally diagnosed as having a depressive disorder, yet the depressive symptoms were judged to be less severe for the elderly patient. Furthermore, antidepressive medication was judged to be less appropriate for the older patient. This indicates that although in many circumstances, symptom severity ratings and diagnostic ratings may be correlated, there may be times when differences in these judgments are most telling. Furthermore, by separating these types of judgments, one can test the hypothesis that there are different underlying processes associated with these types of judgment. At this time, the potential gains from distinguishing between diagnostic-type biases and symptom severity-type biases appear to outweigh the possible limitations.

\section{Evidence for Patient Variable Biases}

I now examine the available evidence for clinical judgment biases. All studies that meet the criteria for this review are organized in Table 1 by the type of patient variable under study (gender, race, social class, age, mental retardation, ethnicity, and other), by the type of judgments studied (severity or diagnosis), by whether evidence of bias was found, and by the type of bias found (overpathologizing, mininimizing, overdiagnostic, and underdiagnostic). A total of 60 studies are included, from which 103 cases were derived. A case refers to the unit of analysis for a given patient variable effect, in other words, the judgments associated with a given case summary or group of patients. Because most investigations examined the judgments or treatment of one type of disorder or one patient group, most studies gener- ated only one case. Other studies, however, assessed the judgments of more than one disorder or group of disorders. For example, Rosenfield (1982) assessed gender differences in the hospitalization rate of patients with neuroses/psychotic depression, schizophrenia, and personality/substance abuse disorders. Studies such as these were noted as having as many cases as types of disorders examined. By considering the type of disorder, the relationship between type of disorder and biased judgments can be assessed, a relationship that has not been examined sufficiently in past reviews. In Table 1, the disorder that pertains to each case is parenthetically noted beneath each reference to the study in order to denote multiple cases in a given study. No mention of the disorder is made for those studies with only one case.

For some studies, a further distinction was made with reference to cases. Some investigations of only one case reported both an overdiagnostic and an underdiagnostic bias. For example, Mukherjee et al. (1983) reported that Black and Hispanic patients with bipolar disorders were more likely misdiagnosed as having schizophrenia than were Caucasian patients with bipolar disorders. These findings were interpreted as reflecting both an overdiagnosis of schizophrenia and an underdiagnosis of bipolar disorders. Because the finding of both biases is based on the identical finding, each case of bias was assigned a weight of one half for this review. This procedure was used to guard against counting one finding of bias as two findings.

It should also be noted that there are studies that examined the effect of more than one patient variable (e.g., gender and race) on treatment practices or clinical judgments. Because some studies reported evidence of bias for one patient variable and not another (e.g., Benson, 1983; Settin, 1982), the results for the different patient variables were tabulated as separate cases. This procedure was adhered to for all studies that examined the effects of multiple patient variables, including those studies for which no evidence of bias was found for multiple patient variables (e.g., Bamgbose, Edwards, \& Johnson, 1980; Schwartz \& Abramowitz, 1975).

Old versus new definition of bias. Having identified the number of potential cases, I can now assess the significance of broadening the definition of bias. Table 2 summarizes the number of cases of no bias and the number of cases of the different types of bias by the patient variable under investigation. In addition, the proportion of cases that reveal bias, on the basis of the old and new definitions of bias, is calculated for severity judgments and for diagnostic judgments. In regard to severity judgments, the old definition of bias refers to only the overpathologizing bias, whereas the new definition of bias refers to both the overpathologizing and the minimizing biases. Consider, for example, gender bias in cases involving severity judgments. The proportion of gender bias cases when using the old definition is 4 of 32 or .125 and when using the new definition is 9 of 32 or .28 . The same procedures were used in calculating the proportion of bias cases for diagnostic judgments. The old definition of bias refers to only the cases of overdiagnosis, and the new definition refers to cases of both over- and underdiagnosis.

An examination of the proportions of bias across all patient variables reveals that when applying the old definition of bias, .24 of the severity-related cases and .22 of the diagnostic cases (text continues on page 19I) 


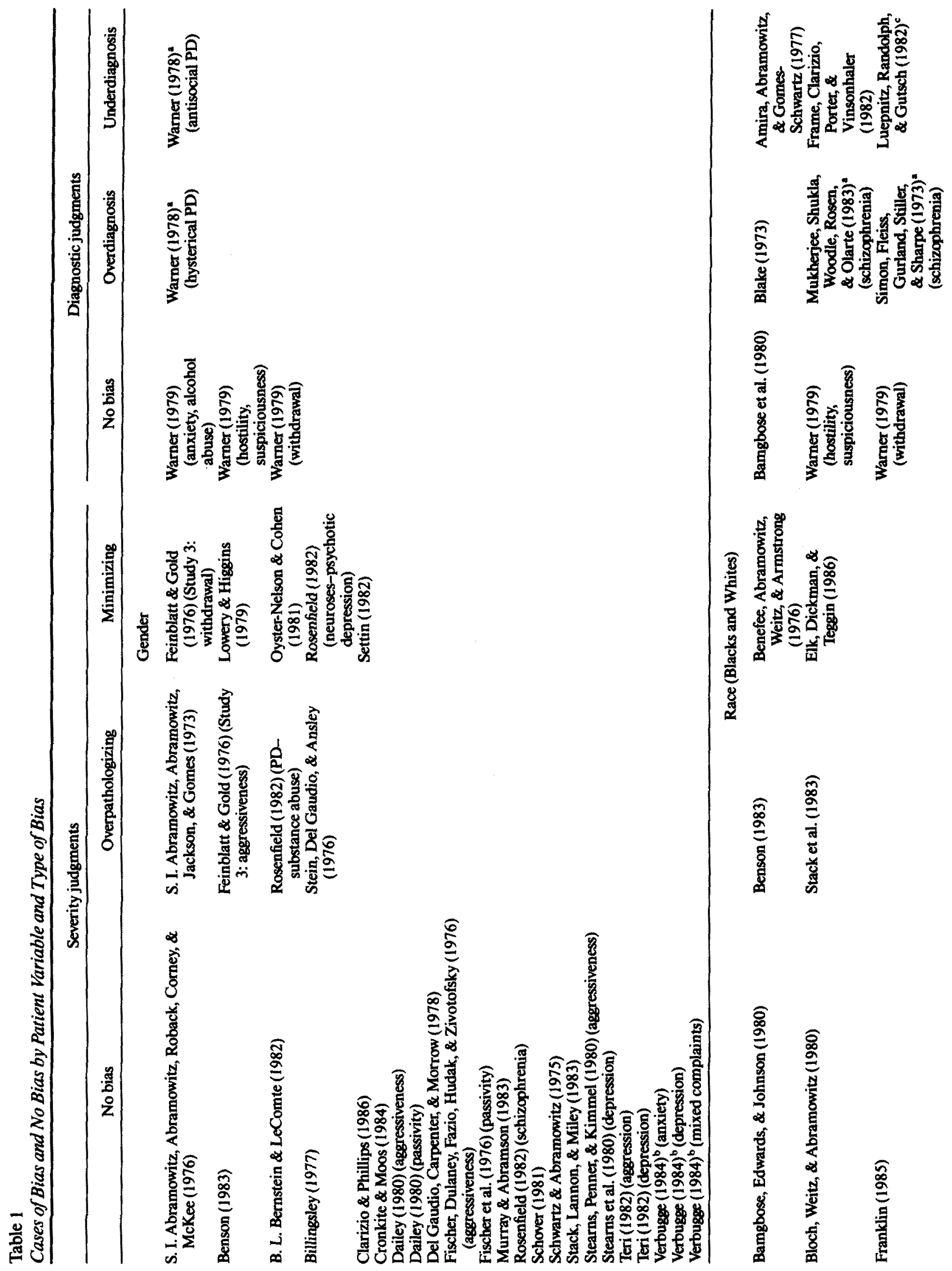




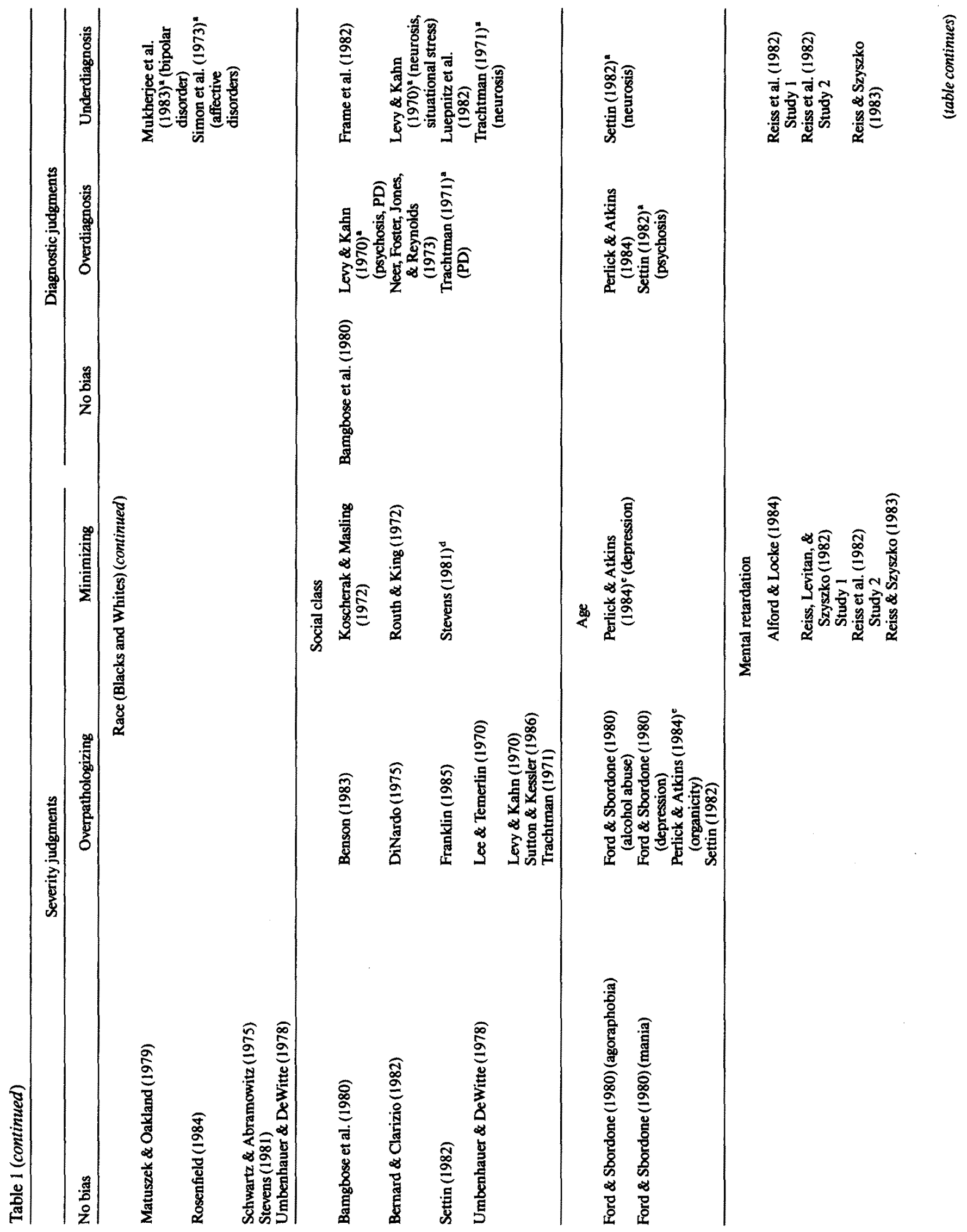




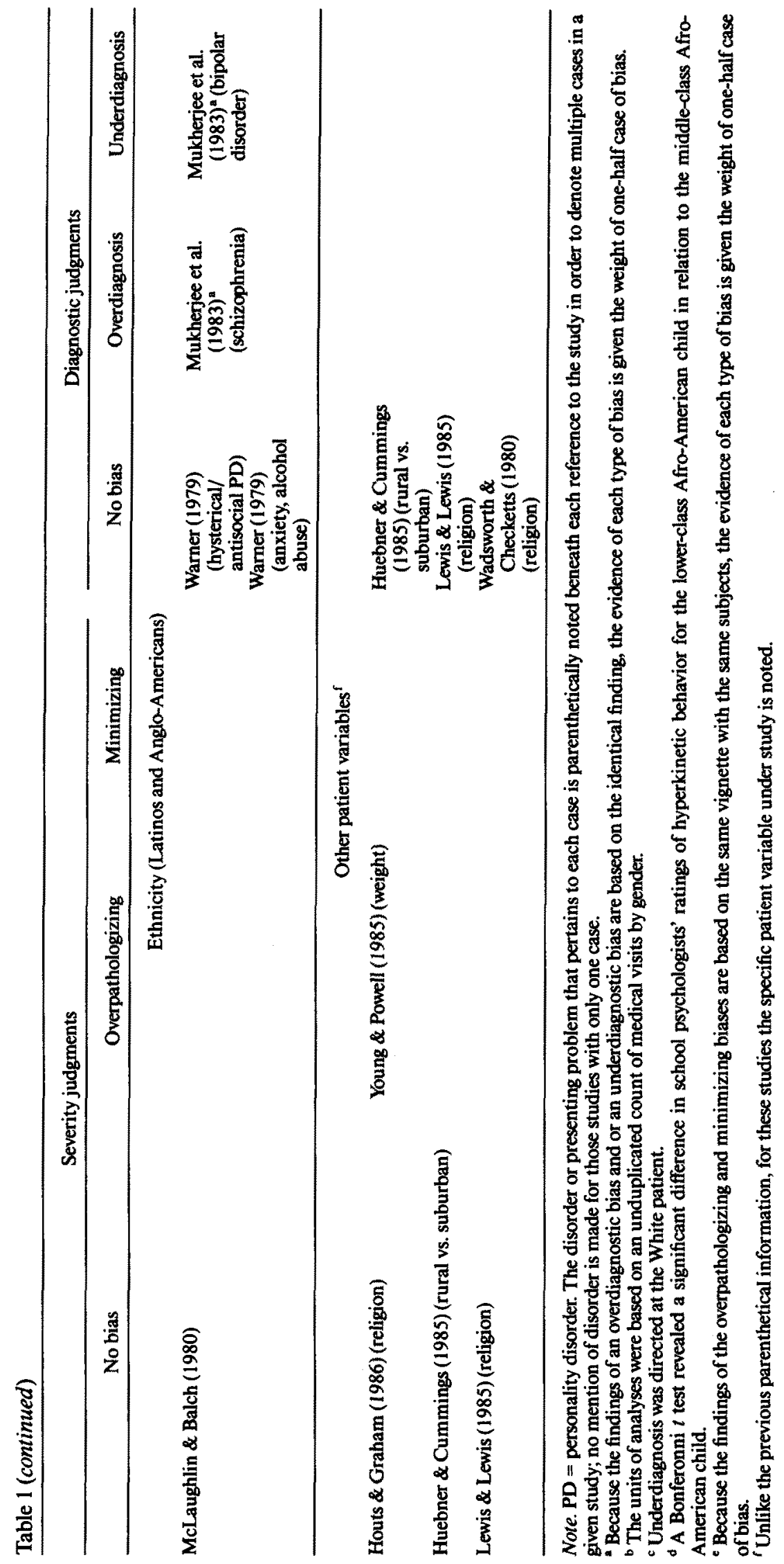


Table 2

Frequency and Proportion of Bias Cases by Patient Variable

\begin{tabular}{|c|c|c|c|c|c|c|c|c|c|c|}
\hline \multirow[b]{2}{*}{ Patient variable } & \multicolumn{3}{|c|}{ Severity judgment bias } & \multicolumn{2}{|c|}{$\begin{array}{l}\text { Proportion of } \\
\text { bias cases }\end{array}$} & \multicolumn{3}{|c|}{ Diagnostic judgment biases } & \multicolumn{2}{|c|}{$\begin{array}{l}\text { Proportion of } \\
\text { bias cases }\end{array}$} \\
\hline & No bias & $\begin{array}{c}\text { Over- } \\
\text { pathologizing }\end{array}$ & Minimizing & $\begin{array}{c}\text { Old } \\
\text { definition }\end{array}$ & $\begin{array}{c}\text { New } \\
\text { definition }\end{array}$ & No bias & $\begin{array}{c}\text { Over- } \\
\text { diagnostic }\end{array}$ & $\begin{array}{l}\text { Under- } \\
\text { diagnostic }\end{array}$ & $\begin{array}{c}\text { Old } \\
\text { definition }\end{array}$ & $\begin{array}{c}\text { New } \\
\text { definition }\end{array}$ \\
\hline Gender & 23 & 4 & 5 & 0.12 & 0.28 & 3 & 0.5 & 0.5 & 0.12 & 0.25 \\
\hline Race $^{a}$ & 8 & 2 & 2 & 0.17 & 0.33 & 3 & 2 & 4 & 0.22 & 0.67 \\
\hline Social class & 4 & $\overline{7}$ & 3 & 0.50 & 0.71 & 1 & 2 & 3 & 0.33 & 0.83 \\
\hline Ethnicity ${ }^{b}$ & 1 & 0 & 0 & 0.00 & 0.00 & 2 & 0.5 & 0.5 & 0.17 & 0.33 \\
\hline Religion & 2 & 0 & 0 & 0.00 & 0.00 & 2 & 0 & 0 & 0.00 & 0.00 \\
\hline Otherc & 1 & 1 & 0 & 0.50 & 0.50 & 1 & 0 & 0 & 0.00 & 0.00 \\
\hline Total & 41 & 17.5 & 14.5 & 0.24 & 0.44 & 12 & 6.5 & 11.5 & 0.22 & 0.60 \\
\hline
\end{tabular}

la Race refers to Blacks and Whites. ${ }^{\mathrm{b}}$ Ethnicity refers to Latinos and Anglo-Americans (Whites). ${ }^{\mathrm{c}}$ Patient variables include weight and rural vs. suburban place of residence.

show evidence of bias. In contrast, when applying the new defnition, .44 and .60 of the respective cases reveal judgment biases. Past reviews are consistent with the findings obtained when using the old definition of bias; the great majority of cases reveal no bias (C. V. Abramowitz \& Dokecki, 1977; S. I. Abramowitz \& Murray, 1983; Davidson \& S. I. Abramowitz, 1980; Zeldow, 1978). In contrast, when one applies the new definition, there is almost twice as much evidence of bias. To assess whether the proportion of bias cases found using the old and new definitions differs from what one would expect by chance, I arranged the number of cases in $2 \times 2$ (Bias/no bias $\times$ New and old definitions) contingency tables (see Table 3 ) and then analyzed them using McNemar's test for correlated samples (Fleiss, 1981). The results reveal that the proportion of biased cases is statistically different when using the two definitions both for severity judgments, $\chi^{2}(1, N=72)=12.57, p<.001$, and for diagnostic judgments, $\chi^{2}(1, N=30)=9.59, p<.005$. These findings point out the importance of redefining bias. By adding the minimizing and underdiagnostic biases to the old definitions of bias, one finds significantly more evidence of bias.

One alternative explanation for the differences in proportions

Table 3

Number of Bias Cases With Old and New Definitions of Bias

\begin{tabular}{llcc}
\hline \multirow{4}{*}{$\begin{array}{c}\text { New } \\
\text { definition }\end{array}$} & \multicolumn{3}{c}{ Old definition } \\
\cline { 2 - 4 } & Bias & No bias & Total \\
\hline & \multicolumn{2}{c}{ Severity judgments } \\
Bias & 17.5 & 14.5 & 32 \\
No bias & 0.0 & 41.0 & 41 \\
Total & 17.5 & 55.5 & 73 \\
\hline \multicolumn{5}{c}{ Diagnostic judgments } \\
Bias & 6.5 & 11.5 & \\
No bias & 0.0 & 12.0 & 18 \\
Total & 6.5 & 23.5 & 12 \\
\hline
\end{tabular}

is that the number of cases of bias is inflated because one study can generate more than one case. The multiple-case studies may have contributed a disproportionate share of cases revealing bias. To test this plausible explanation, I conducted the McNemar test for those studies with only one case. The proportion of cases that found bias using the old and new definitions was still found to be statistically different for severity judgments $\left(p_{\text {old }}=.26, p_{\text {new }}=.50, \chi^{2}(1, N=52)=10.58, p<.005\right)$ and diagnostic judgments $\left(p_{\text {old }}=.27, p_{\text {new }}=.77, \chi^{2}(1, N=22)=\right.$ $9.09, p<.005)$. A second alternative explanation is that the number of bias cases is inflated because studies that examined multiple patient variable effects contributed more than one case of bias. To test this explanation, I removed from the analysis those studies that tested more than one patient variable effect. Again, the proportion of cases that found bias differed using the old and new definitions (severity judgments: $p_{\text {old }}=.23, p_{\text {new }}=$ $.45, \chi^{2}(1, N=55)=10.58, p<.005$; diagnostic judgments: $\left.p_{\text {old }}=.30, p_{\text {new }}=.80, \chi^{2}(1, N=15)=5.63, p<.025\right)$. These findings indicate that the difference in the proportion of biased cases when using the two definitions of bias is not the result of studies contributing more than one case to this review.

Specific patient variable effects. Having demonstrated that the proportion of biased cases is greater when using the new definition of bias, it is worthwhile to examine the extent to which this overall finding applies to each of the patient variables under study. The small number of studies for each patient variable, however, prohibits applying McNemar's test for such a fine-grained analysis. Nevertheless, a review of Table 2 by patient variable does indicate those situations in which investigators have been more or less successful in uncovering clinical judgment bias. The only patient variable bias that has received consistent evidence of bias is mental retardation. All of the seven cases reveal bias, either a minimizing bias or an underdiagnostic bias. Social class is the variable that has received the second most consistent support of bias. Over three fourths of the known cases show possible clinical error for both severity and diagnostic judgments; the overpathologizing bias is the type of bias that most frequently receives empirical support. It is 
worth noting that just over 10 years ago, social class was noted as being the only patient variable to consistently demonstrate bias (C. V. Abramowitz \& Dokecki, 1977). Bias is also consistently revealed in diagnostic judgments of Black and White patients; six of nine cases reveal a diagnostic bias. This is the first time that consistent findings of race bias are noted in a review of psychotherapy bias. Unlike the social class and mental retardation biases, race bias is found regularly only in diagnostic judgments and not in severity judgments. Of the three variables most frequently studied (gender, race, and social class), gender has received the least consistent evidence of bias. Interestingly, investigators have focused almost exclusively on severity judgments; only one investigator has examined the effect of gender on diagnostic judgments (Warner, 1978, 1979).

\section{Summary}

The available evidence points out the importance of broadening the definition of bias from the overpathologizing and overdiagnostic biases to the inclusion of minimizing and underdiagnostic biases. By doing so, there are nearly twice as many findings of bias with the new definition as with the old definition. Moreover, in contrast to past reviews that found little evidence of bias, this review indicates that there is about equal evidence of bias as there is evidence of no bias. The most consistent support for bias pertains to the mentally retarded and to lower social class members. There is some consistent evidence of race bias with diagnostic judgments, whereas there is the least consistent evidence of gender bias with both diagnostic and severity judgments.

\section{Conceptualization of the Biased Clinician}

Broadening the definition of bias may not only assist researchers in uncovering patient variable errors, but it may also contribute to a refinement of our conceptualization of the biased therapist. A significant assumption underlying much of the past research is that bias should be elicited by the patient's gender or other salient characteristic, irrespective of other patient attributes. Accordingly, the biased clinician is portrayed as a prejudiced individual who makes judgments based primarily on a single characteristic. Consider the effect of patient's gender. If bias exists, according to this view, female patients should be judged as more impaired and as requiring less than quality treatment, even with well-defined cases of psychopathology. Although there may be some therapists practicing today who fit this rather extreme model of bias, it is unlikely that many therapists do. Therefore, it should be of little surprise that there is little evidence to support this view of the biased mental health practitioner.

In this article, I offer a different conceptualization. In contrast to the prejudiced individual who makes judgments irrespective of the situation, I argue that the biased clinician is like any other information processor who has to synthesize much complex information to make decisions regarding diagnosis and treatment. Like many decision makers, clinicians use shortcuts. This is evident, for example, in the initial interview. A clinician does not have the time to inquire systematically about all possible symptoms of psychopathology. Instead, he or she uses whatever information is available (e.g., affect, gait, speech, personal hygiene, history) to develop hypotheses regarding the patient's disorder. Patient characteristics such as age, race, gender, and social class are believed to influence the development of these hypotheses in ways that result in systematic errors in the evaluation of certain disorders for certain patient groups. For example, a therapist may be more apt to diagnose alcoholism for a lower-class Black patient than for a middle-class White patient who both have identical symptoms (Luepnitz et al., 1982). Or a 75-year-old patient with depressive symptoms including memory difficulties may more likely be identified as demented than would a 55-year-old patient with the same symptoms (Perlick \& Atkins, 1984).

A contributing factor to the selective information processing of the biased clinician is that clinicians may attempt to consider important group differences suggested by the patients' race, ethnicity, age, and even gender. On the one hand, therapists are instructed not to differentially evaluate or treat patients on the basis of their background, because this may be reflective of prejudicial attitudes. On the other hand, therapists are instructed to differentially evaluate and treat patients because of the different norms that pertain to patients of different backgrounds. For example, there is research that suggests that premenopausal women with schizophrenia are more receptive to neuroleptics than are men with schizophrenia (Seeman, 1986). As a result, female patients may require smaller doses than their male counterparts. If this is so, physicians who medicate men and women equally may err by not taking into account this purported gender difference. Similarly, the risk of a fatal suicide attempt is greatest among the elderly (McIntosh, 1985; Pfeiffer, 1977). As a result, clinicians are correct when they attend more to suicidal ideation among this group than to suicidal ideation among younger patient groups (Gatz, Popkin, Pino, \& VandenBos, 1985). In these two examples, a failure to consider adjusting one's clinical judgments according to the patient's gender or age represents a major error.

Although it is important to take into account group differences, doing so could also lead to error in judgments of individuals. It is unlikely that all women are more sensitive to neuroleptics than are men and that all the elderly with suicidal ideation will intentionally end their lives. Perhaps considering gender differences in neuroleptic sensitivity and age differences in suicidality will at times lead physicians to undermedicate female patients and will at times lead evaluators to overpathologize suicidal thoughts of elderly patients. In order to avoid potential errors in judgment, it is important that clinicians conduct a most thorough evaluation of individual patients from groups in which norms may be adjusted (see López \& Hernandez, 1986). The relevance of this issue for the study of clinical judgment bias is that a clinician who makes errors in adjusting norms or failing to adjust norms is likely to be conceptually distinct from the clinician who makes errors because of prejudicial attitudes.

Two sources of evidence support the information-processing model of the biased clinician. The first group of studies indicates that bias may frequently be problem specific. In other words, error in clinical judgment may be more likely to occur for particular symptoms, problems, or disorders. Findings that support the problem-specificity notion are contrary to the prej- 
udiced-therapist notion because prejudiced therapists should demonstrate negative attitudes across most, if not all, presenting problems. The second group of studies indicates that clinicians make systematic errors in clinical judgments of men, Whites, and middle social class members as well as of women, Blacks, and lower social class members. Evidence that therapists err in their judgments of patients from groups who are not traditionally subject to discrimination supports the notion that errors based on patient variables are the result of selective information processing rather than of the previously assumed prejudicial sentiments.

\section{Disorder or Symptom Specificity of Biased Clinical Judgment}

Suggestive evidence of symptom or disorder specificity can be found in the study of gender bias. The findings of a minimizing bias against women occurred in the evaluation of feminine gender role symptomatology, that is, symptoms that reflect internalizing distress, such as depression and anxiety (Horwitz \& White, 1987). In three of the studies (Oyster-Nelson \& Cohen, 1981; Rosenfield, 1982; Settin, 1982), clinicians evaluated depressive symptoms or disorders, and in the other study (Feinblatt \& Gold, 1976, Study 3), clinicians evaluated problems of social withdrawal, emotionality, and unassertiveness. Taken together, these findings are consistent with the notion that women who present symptoms that are perceived to be related to their gender role will be judged as less disturbed than men with the same symptoms. It is worth noting that there are other studies that examined mental health treatment practices regarding patients with feminine gender role symptoms that did not reveal a minimizing bias (e.g., Stein et al., 1976; Verbugge, 1984).

Studies of race and ethnic bias also provide some evidence that specific disorders/symptoms, that is, schizophrenia and bipolar disorders, appear to be linked to specific biases. The available evidence suggests that being Black or Hispanic may increase patients' chances of being misdiagnosed as having schizophrenia when in fact they are suffering from a bipolar disorder. Two studies support the overdiagnosis of schizophrenia for Black patients (Mukherjee et al., 1983; Simon et al., 1973), and one study supports this same bias for Hispanic patients (Mukherjee et al., 1983). The same studies support the underdiagnosis of bipolar and affective disorders for Blacks and the underdiagnosis of bipolar disorders for Hispanics. Consistent with these findings is a recent study that suggests that depressive symptoms of South African Black patients are not properly treated (Elk, Dickman, \& Teggin, 1986).

Although there is some support for the problem-specificity notion of bias for research of the patient's gender and race, there is little or no support for this notion for research of other patient variables. In the study of social class bias, the majority of studies either did not specify the presenting prablems/disorders or examined the evaluation process across several problems/disorders. Therefore, the relationship between symptoms and type of bias cannot be ascertained at this time. Three studies of age bias provide what appear to be contradictory findings regarding the type of bias that corresponds to the evaluation of depression. Two studies found evidence that older patients are judged to be more depressed than middle-aged patients (Ford \& Sbor- done, 1980; Settin, 1982), and one study found evidence that the older patient is judged to be less depressed than the middleaged patient (Perlick \& Atkins, 1984). Finally, the problemspecificity notion was not at all evident in the study of the mental retardation label. The disorders associated with the mentally retarded patients were all judged to represent less pathology and were less likely to be accurately diagnosed. At this time, the type of disorder or symptom appears to be unrelated to biased judgment of patients identified as mentally retarded, and it is unclear whether specific symptoms or disorders are more likely to lead to biased judgments of lower social class patients and elderly patients.

\section{Biases in Judgment Against Nonoppressed Group Members}

The second group of findings that support an informationprocessing model of the biased clinician indicates that there may be some occasions when evaluators err in judging traditionally nonoppressed group members as a function of their race or gender. This is most clearly indicated in a study of the effect of race and social class on the diagnosis of alcoholism. Luepnitz et al. (1982) found that psychology trainees diagnosed the Black lower-class patient as much more likely to have a chronic alcohol abuse disorder than the White lower-class patient or the Black and White higher-class patients. At first glance, this finding seems to reflect an overdiagnosis of alcohol abuse for Black lower-class patients. However, because the patient was described as exhibiting symptoms consistent with the DSM-III diagnosis of alcohol abuse, the judgments of the Black lower-class patient were accurate. The diagnostic bias was, in fact, directed at the higher-class patient and, to a lesser extent, at the White patient. This study is consistent with a much earlier study in which alcoholism was underdiagnosed among patients who were socially integrated (Blane, Overton, \& Chafetz, 1963).

In another study, Leinhardt, Seewald, and Zigmond (1982) found that the overall sample of learning disabled (LD) children contained a disproportion number of White boys. One way of assessing the appropriateness of these placements was to examine the students' performances on achievement tests. There were significantly more White male achievers in these classes than there were White male underachievers. In contrast, there were significantly more underachievers among the Black and female students in these classes. These findings suggest that White male students were most prone to be inappropriately placed in LD classes and that Black and female students were most likely to be appropriately placed. These findings are similar to those in the alcoholism study in that the LD diagnostic and placement bias appears to be directed at the White male student. This study, however, falls short of an experimental study conclusively demonstrating the bias against the White male student. The ex post facto study design also leaves open the possibility that some other variable besides race and gender better accounts for the results. Nevertheless, an experimental study did in fact corroborate the general findings of the Leinhardt et al. study. As is noted in Table 1, Amira, Abramowitz, and Gomes-Schwartz (1977) found that a learning disability diagnosis was judged to be more appropriate for the case report 
depicted as a White student than for the case report depicted as a Black student.

\section{Conclusion: Implications for Research and Training}

Although limited, the available research suggests that bias can be problem specific and that bias can be directed against nonoppressed group members. If these observations continue to receive empirical support, then this would further indicate that the information-processing model of the biased clinician is an appropriate conceptual model.

This conceptual framework has several implications for future research. First of all, systematic errors in judgment based on patient variables may pertain to all clinicians and not just to those clinicians with prejudicial attitudes. This suggests that less emphasis should be placed on therapists' social values and more emphasis should be placed on the general processes that lead to judgment error. Second, investigators should give careful consideration to the symptoms or disorders used as their clinical stimuli, at least among studies of gender and racial/ethnic bias. Third, if there is evidence for bias with the present conceptualization, then the implications for training clinicians to prevent such biases will differ greatly from the original model. Although never addressed, the training implication of the old model was to change attitudes or values. The present conceptualization suggests that clinicians can be trained to improve the way in which they process information (See Arkes, 1981; Arnoult \& Anderson, 1988; Turk \& Salovey, 1986).

\section{Toward a Theoretical Perspective}

The selective information-processing model of clinical judgment bias is partially supported by the previously reviewed literature. Before such a model can be accepted as valid, more direct evidence is needed of the selective information processes underlying systematic errors in clinical judgment. Accordingly, this section examines cognitive processes that may underlie the biased clinical judgment process. The theoretical foundations of this discussion lie in the study of social cognition (Fiske $\&$ Taylor, 1984; Higgins \& Bargh, 1987) and of judgment and decision making (Arkes \& Hammond, 1986; Einhorn \& Hogarth, 1981; Kahneman, Slovic, \& Tversky, 1982; Turk \& Salovey, 1988). Some of the notions from these research areas have already been applied to the patient variable bias literature, but most have not. It should be noted that the identified theoretical notions are not comprehensive. Instead, some key notions are discussed with an eye toward developing a theoretical perspective in the study of patient variable biases in clinical judgment.

I organized this section into five areas. In the first part, I examine how patient variables may affect clinicians' attributions of specific presenting problems, which may in turn affect clinical judgments. Second, I consider base rates or subjective probability judgments that certain problems or disorders occur with certain patient groups. Of particular importance is the relationship between base rates and clinical judgments. Third, I discuss research concerning how memory affects judgments. The study of retrieval and its relationship to stereotyping is examined as well as the possible relationship of semantic and episodic memory to clinical judgment. Last, I provide a brief overview of the study of hypothesis testing. Of particular relevance to the study of patient variable bias is the confirmatory strategy of hypothesis testing. Because of the limited research that examines these processes as they relate to the study of clinical judgment bias, in this section I included relevant studies that may not meet the strict criteria used in the first section of this review.

\section{Attributions}

Studies indicate that background variables such as race (Duncan, 1976; Yarkin, Town, \& Wallston, 1982), gender (Deaux, 1976), religious affiliation (Taylor \& Jaggi, 1974), and mental retardation label (Severance \& Gasstrom, 1977; Weisz, 1981) can affect the types of attributions nonclinicians make in judging behavior. For example, Weisz (1981) investigated college students' attributions of the task performance of a child labeled as mentally retarded in one condition and labeled as not mentally retarded in the other condition. He found that raters attributed the retarded child's failure more to the lack of ability and the normal child's failure more to the lack of effort.

Similar attributional processes have been suggested in the clinical literature. One survey identified occasions when therapists misattributed presenting problems of female patients to internal factors rather than to situational factors (American Psychological Association, 1975; Task Force on Sex Bias and Sex-Role Stereotyping in Psychotherapeutic Practice, 1978). In the experimental literature, Bowman (1982) and Perlick and Atkins (1984) reported data suggesting that clinicians entertain different attributions on the basis of the patient's gender and age. Bowman found differences in therapists' formulations of the problem of a hypothetical patient who was presented in a manner consistent with a masculine sex role (a career-oriented person with a high level of activity). For the male patient, the problem was attributed to having difficulty in dealing with anger. In contrast, the identical problem in the female patient was more frequently attributed to conflict about sexual identity and dominance in marriage. In a study of age bias, Perlick and Atkins found that clinical psychologists were more likely to ascribe organic causes to an elderly patient's depressive symptoms and to ascribe functional causes to a middle-aged patient's depressive symptoms.

Of most importance is the relationship between differential attributions and clinical judgment. In each of the reported experimental studies, significant differences were found in the clinicians' judgments across the two patient conditions. In the Bowman (1982) study, it was more frequently noted that the treatment of the female patient in relation to that of the male patient should focus on achieving a "satisfactory balance of roles between home and career" (p. 352). Also, insight-oriented treatment was recommended more for the female patient, and couples therapy was recommended more for the male patient. Although the correlations between the clinicians' attributions and treatment recommendations were not reported, the treatment recommendations appear to be consistent with the clinicians' formulations (attributions) for the female and male patients. Similar findings were presented in the study of elderly bias. The older patient was judged to be less depressed, more cognitively impaired, and less likely to benefit from antidepressive medication than was the middle-aged patient. 
These studies, although few in number, suggest that clinicians' causal ascriptions may be important in understanding patient variable biases in clinical judgment. Future work in this area would benefit from empirical tests of the attributional ratings with clinical judgments and from applications of attribution theory to systematically guide this specific area of research. Weiner's $(1985,1986)$ attribution theory may be of particular relevance because it considers phenomena that are central to clinical judgments, such as expectancy judgments (prognosis) and help giving (willingness to provide therapy). Preliminary work in this area indicates that the theory is most applicable to clinical judgment (López, 1983a).

\section{Base Rates}

A second conceptual factor that may be relevant to our understanding of judgment bias is the base rates or subjective probabilities that clinicians hold about specific patient groups having certain symptoms and disorders. The notion that Blacks suffer from schizophrenia more than Whites is an example of differential base rates. There are few studies that have directly investigated whether mental health practitioners hold differential base rates. López (1983a) asked clinicians to rate the likelihood of certain mental health-related problems pertaining to Mexican immigrants and to Anglo-Americans. He found that certain problems were judged to occur more for Mexican immigrants (e.g., a woman's passive response to marital problems and an adolescent's involvement in gang activities). Other problems were judged more likely to occur for Anglo-Americans, such as symptoms suggestive of a bipolar disorder and of the "empty nest syndrome." Still others, such as psychotic symptoms, were judged to occur equally for both groups. In a study of age bias, Wolkenstein and López (1988), found that mental health professionals believed that depressive disorders/symptoms and dementia-related disorders/symptoms were more prevalent among older adults (65 years and older) than among middleaged adults (55-65 years old). A third study examined physicians' base rates of psychological symptoms for men and women. B. Bernstein and Kane (1981)reported that physicians judged women as more likely than men to have emotional lability, psychosomatic illness, headaches, and numerous minor complaints.

Although it is important to identify the differential base rates held by clinicians, it is most important to examine if these base rates are related to biased clinical judgment. López (1983a) did not find any relationship between clinicians' base rates of Mexican immigrants' and Anglo-Americans' presenting problems and their judgments of case reports based on these presenting problems. However, Wolkenstein and López (1988) and B. Bernstein and Kane (1981) found that base rates were indeed related to clinical judgments. The more clinicians believed that dementia-type disorders and symptoms occur more frequently in the elderly, the more likely they diagnosed a case of depression as being both dementia and depression and the less likely they diagnosed the case as depression only (Wolkenstein \& López, 1988). In the evaluation of two case reports, women were judged by physicians as requiring a greater consideration of emotional factors and as having more of a psychosomatic-type disorder than were men (B. Bernstein \& Kane, 1981). Because only three studies have directly examined the relationship between clinicians' differential base rates of mental health symptomatology and their clinical judgments, no conclusions can be drawn at this time. There are, however, a number of clinical judgment studies of mental health practitioners that provide indirect evidence that base rates affect judgments.

The studies consistent with overdiagnostic and underdiagnostic biases suggest that clinicians hold different base rates for Blacks, women, lower social class patients, and mentally retarded patients. Luepnitz et al.'s (1982) finding that lower-class Blacks are diagnosed by clinical psychology trainees as having alcoholism more than lower-class Whites suggests that these subjects hold different racial base rates for alcoholism. Other findings of the same study suggest that the raters also hold different base rates for patients of different social classes: Specifically, members of the lower social class are more likely to have alcoholism than are members of higher social classes. Related research suggests that physicians share this same base rate (Blane et al., 1963; Wolf, Chafetz, Blane, \& Hill, 1965). Leinhardt et al.'s (1982) study of learning disabilities suggests that school evaluators may have differential base rates pertaining to gender and race; specifically, evaluators may believe that male students and White students are more likely to have learning disabilities. Tucker's (1980) study, however, provides contradictory evidence indicating that there are more Blacks in the learning disability classes. Research regarding racial differences in the diagnosis and treatment of affective disorders and schizophrenia (Elk et al., 1986; Raskin, Crook, \& Herman, 1975; Simon et al., 1973) provides additional indirect evidence that mental health practitioners hold specific racial base rates; that is, Black patients are less likely to have affective disorders and more likely to have schizophrenia than White patients. Also, the finding that psychologists underdiagnose mental disorders of mentally retarded individuals (Alford \& Locke, 1984; Reiss et al., 1982; Reiss \& Szyszko, 1983) suggests that psycholfogists may believe that this population suffers less from these disorders. In all, these findings only suggest that clinicians adhere to differential base rates for the specified disorders and the specified patient groups. Clinicians were not directly queried as to their perception regarding these disorders for these groups. Furthermore, these findings may be limited to the specific stimuli and clinical groups studied.

The available research provides suggestive evidence that base rates of specific disorders and symptoms can influence clinicians' diagnostic judgments. If a clinician believes that Blacks are more likely to be alcoholic or schizophrenic, then it is likely that a clinician may bias his or her diagnostic judgments in the direction of these base rates. There are at least two problems with this perspective, however. The first problem is that some research indicates that base rates are not adhered to in decision making. The second problem is that adherence to differential base rates may be representative of accurate judgment instead of erroneous judgment. Each of these problems is addressed here.

Adherence of base rates in decision making. Kahneman and Tversky (1973) were among the first to report that subjects underuse base rates in making decisions. Subjects have been found to use what Kahneman and Tversky referred to as the representativeness heuristic in decision making. In their frequently cited 
study, the judgment that a description of a person represented an engineer or a lawyer was found to be based more on how much the description fit the subject's notion of what an engineer or lawyer was and less on the given base rates of these two professional groups. Social psychologists have found additional support for this phenomenon in social situations, including judgments of assertiveness (Locksley, Borgida, Brekke, \& Hepburn, 1980) and predictions of responses to shock experiments (Nisbett \& Borgida, 1975). The underuse of base rates has been referred to as the base rate fallacy (Bar-Hillel, 1980). If the base rate fallacy accurately depicts how decision makers (do not) use base rates, then it is unlikely that further study of base rates in relation to biases in clinical judgment will be fruitful.

Recent studies, however, indicate that the underuse of base rates may be more circumscribed than previously suggested. Several situations have been identified in which base rates are indeed used. Some of these situations occur when base rates are presented in a concrete and salient fashion (Borgida \& Nisbett, 1977), when base rates fit into intuitive causal theories (Ajzen, 1977; Tversky \& Kahneman, 1980), when the rule of using base rates is accessible to the decision maker (Ginossar \& Trope, 1987), and when base rates facilitate judgments in cognitively demanding decision tasks (Bodenhausen \& Lichtenstein, 1987). In addition, Christensen-Szalanski and Beach (1982) found that more experience with the judgment task leads to a greater adherence to base rates. Using professional judges, other investigators (Wallsten, 1981; Zukier \& Pepitone, 1984) provided further support for this notion; medical students were less likely than the more experienced physicians to use base rates in their judgments. In general, these studies indicate that base rates can influence both social and clinical judgments. Future investigations of patient variable biases in clinical judgments of mental health patients may do best to consider (a) base rates that suggest causal theories, (b) salient patient variables that may elicit greater adherence to base rates, and (c) the effect of clinical experience on the use of base rates.

Einhorn and Hogarth (1981) raised an additional point: It is difficult to determine if base rates are neglected because of the lack of precision in determining the specific base rates that judges use or do not use. For example, in one study of assertiveness judgments of male and female actors (Locksley et al., 1980), college students were found to have gender-linked base rates regarding assertiveness; more men were judged to be assertive than women. However, when judging the assertiveness of the identical interaction for a male actor and a female actor, the gender-linked base rates had little effect on their judgments of the actors' assertiveness. Locksley et al. (1980) argued that the raters failed to use their base rates. Another interpretation of this same finding is that the subjects used different sets of base rates in making their judgments. They may have used general population base rates in judging the likelihood of men's and women's assertiveness. However, when making judgments of how assertive a particular man or woman was, they may have used college student base rates. The point is that the findings in support of the base rate fallacy are held in some doubt because of the lack of precision in defining the base rates used in making judgments. This argument in conjunction with the previously cited research suggests that base rates are still important factors in decision making and that they may be of particular value to investigators of patient variable biases in clinical judgment.

Accuracy of base rates. The second problem with the base rate notion is that adherence to differential base rates may not be indicative of bias or error. Rather, it may be reflective of actual differences in the likelihood of certain disorders occurring for certain groups. It is important to note here that adhering to differential base rates that are supported by epidemiological data does not necessarily reflect accurate judgments of any given individual. For instance, women present themselves to mental health facilities more often with depressive disorders than do men (Weissman \& Klerman, 1977). However, clinicians' judgments that a particular female client is more likely to have a depressive disorder than is a male client with the same symptomatology do not necessarily represent an accurate judgment. Gender should not be the most significant variable considered in the diagnosis of individual cases.

At this time, base rates appear to be central to the study of patient variable biases in clinical judgment. Only through further research will the exact role of base rates in clinical judgment be identified. Research that directly examines the relationship between therapists' base rates and their clinical judgments will make an important contribution.

\section{Memory}

In studying the clinical judgment process, it is important to consider memory. Therapists' recall of clinical material may be significantly influenced by salient patient characteristics such as race, gender, and social class. To date, only three studies have examined some aspect of clinicians' recall in the study of clinical judgment bias. Buczek (1981) examined whether the client's gender affected clinicians' recall and recognition of the information presented by the client. Contrary to the study's hypotheses, clinicians were found to correctly recognize more vocational facts pertaining to the female client than to the male client. This finding is consistent with other research indicating that information that is incongruent with one's expectations or stereotypes may lead to greater recall (Hastie \& Kumar, 1979; Hemsley \& Marmurek, 1982). In the Buczek study it may be that the female client's vocational concerns may have gone against clinicians' expectations of her presenting problems, which in turn may have led to better recall.

Casas and associates (Casas, Brady, \& Ponterotto, 1983; Wampold, Casas, \& Atkinson, 1981) also investigated counselors' recall using an illusory correlation paradigm originated by Chapman and Chapman (1969) and applied to the study of stereotypes (Hamilton, 1981; Hamilton, Dugan \& Trolier, 1985). Casas and associates examined the effect that ethnicity (Wampold et al., 1981) and sexual orientation (Casas et al., 1983) had on counselors' recall of characteristics purportedly pertaining to students of different ethnic background and sexual orientation. In both studies, when the student descriptors were consistent with stereotypic notions of the student's background (e.g., a homosexual described as promiscuous), counselors more accurately recalled the relationship between the student's background and specific characteristics. When the student descriptors were not consistent with stereotypic notions of the student's background (e.g., a Chicano residing in an exclusive area), 
counselors made more errors in recall. These studies suggest that counselors may more accurately recall information about clients when the information is consistent with their stereotypes of the different client groups, and that counselors may have more difficulty in recalling information about clients that is inconsistent with their stereotypic notions of the client group.

The research pertaining to memory and clinical judgment bias is limited, yet it already presents what appears to be conflicting evidence regarding the effect that stereotype-congruent and stereotype-incongruent information have on recall. These findings mirror those found in the study of person perception. Hastie and Kumar (1979) provided evidence that incongruent information leads to greater recall, whereas Rothbart (1981) and Hamilton (1981) provided evidence to the contrary. Although it is beyond the scope of this review to explain this apparent discrepancy (see Fiske and Taylor [1984], Hastie [1981], and Higgins and Bargh [1987] for a more detailed discussion), it is important to note that a consideration of recall in the study of clinical judgment can tap the same issues that arise outside the clinical realm in the study of memory and judgment. Furthermore, these effects may have significant implications for clinical judgments. For example, the failure to recall information may lead to underdiagnosing certain disorders for certain groups.

Recall is only one area in the study of memory as it relates to judgmental processes. The study of encoding or how information is selectively summarized and stored in memory (Rothbart, 1981) may also shed some light on clinical judgment bias. For example, Park and Rothbart (1982) provided evidence that individuals may have a more complex memory structure for ingroup members and a less complex memory structure for outgroup members. Therefore, individuals may be unable to properly categorize and remember information about an out-group member because of the more limiting memory structure. For example, White clinicians who have limited contact with Black patients may have a more homogeneous view of Black patients (i.e., most of them are likely to suffer from schizophrenia), and as a result, they may be less able to recall information (such as affective symptoms) that may deviate from this limited view. Consequently, a more limited range of diagnoses may be considered for Black patients.

Another area within the study of memory that may be particularly fruitful is the study of clinicians' semantic and episodic memory and their ability to distinguish between internal inferences and external data. As was noted by Fiske and Taylor (1984), individuals may not be able to distinguish between their memory of raw data (episodic memory) and their inferences or interpretations of raw data (semantic memory). Accurate evaluations and diagnoses appear to be dependent on clinicians' ability to distinguish between their recollection of the presenting problems and related data and any inferences or judgments made about these data (such as symptom identification, diagnostic formulation, and etiological assumption). If raw data are not encoded and inferences are, then this may greatly impede clinicians' ability to continue gathering evidence to test diagnostic impressions and related hypotheses. As a result, hypotheses may be prematurely accepted as valid. Of particular importance to the study of bias in clinical judgment is that specific patient variables may influence practitioners' ability to distin- guish between episodic memory and semantic memory. For example, they may encode depressive symptoms of a male patient and may not encode the same symptoms of a female patient because of the belief or judgment (which is encoded) that these symptoms are representative of normative behavior for the woman.

\section{Hypothesis Testing}

A final theoretical notion that is considered in the study of clinical judgment bias is hypothesis testing. Medical decisionmaking research has demonstrated that physicians develop hypotheses early in diagnostic evaluations (Elstein, Shulman, \& Sprafka, 1978; Kassirer \& Gorry, 1978; Polister, 1981; Wallsten, 1981). These hypotheses may then guide practitioners' evaluations of such hypotheses. There is some evidence to indicate that physicians use confirmatory strategies to test their hypotheses; that is, they may be more likely to consider information that is consistent with their hypotheses and to devalue information that is inconsistent with their hypotheses (Elstein et al., 1978; Polister, 1981). Evidence for the confirmatory bias has also been found in experimental decision research (Mynatt, Doherty, \& Tweney, 1978) and social psychological research (Snyder \& Swann, 1978; Snyder \& Thomsen, 1988).

The study of bias against older patients and mentally retarded children suggests that such a confirmatory bias may also occur in mental health evaluations. In Perlick and Atkins' (1984) study, depressive symptoms unrelated to cognitive functioning may have been underweighted or undervalued in the diagnosis of the elderly patient, whereas cognitive symptoms may have been more readily accepted in confirmation with clinicians' early hypotheses of organic impairment. Wolkenstein and Ló pez (1988) found support for this pattern in their partial replication of the Perlick and Atkins study. Specifically, clinicians' hypotheses of organic impairment were positively correlated to diagnoses of dementia and were negatively correlated to diagnoses of depression. In the study of diagnostic errors of a mentally retarded child (Reiss et al., 1982), psychopathological features may have been given less credence when the child was labeled mentally retarded than when the child was not so labeled. These three studies provide beginning evidence that a confirmatory bias may occur in evaluations of psychopathology.

The consideration of hypothesis testing points out the continuous ongoing nature of clinical judgment, whether a single session or multiple sessions are investigated. Past research in the study of patient variable biases has generally been characterized by single episodes of a fixed set of information. The dynamic and interactive nature of the clinical judgment process, whereby the clinician is searching for information and interpreting and evaluating hypotheses, more accurately represents the clinical decision-making process. The study of hypothesis testing is likely to contribute to improving the ecological validity in the study of patient variable biases in clinical judgment.

\section{Conclusion}

The application of social cognitive and decision-making theory may advance our understanding of patient variable biases in clinical judgment. Clinicians are believed to be actively en- 
coding, interpreting, making causal attributions, using their memory, generating hypotheses, testing hypotheses, and considering past experiences via their base rates. Each of these cognitive processes can conceivably be influenced by a specific patient variable and as a result bias a therapist's judgments. Because of the limited data, it is premature at this time to relate the specific processes to the previously noted types of bias. Nevertheless, the study of these cognitive factors in relation to patient variable biases in clinical judgment has the potential of contributing significantly to the development of a much needed theoretical model. The testing of this conceptual framework can also contribute to the development of the social cognition and decision-making literature.

\section{Methodological Considerations and Recommendations for Future Research}

The conceptual issues identified in this review raise some questions about methodology. In this last section, I briefly address four methodological concerns: (a) the use of a standard to determine error in clinical judgment, (b) the ambiguity of the clinical stimuli, (c) the nature of the clinical stimuli (case reports vs. videotaped interviews), and (d) the role of analogue methods and social desirability. Also, I identify specific content areas in which empirical research has been particularly limited.

As was noted earlier, the consideration of additional biases besides the overpathologizing bias creates some difficulty in interpreting the directionality of the judgment error. This is further compounded by the notion that clinicians can systematically err in evaluating nonoppressed group members. How does one then determine whether judgments of less severity for women are representive of the minimizing bias against women, the overpathologizing bias against men, or both? One methodological approach in dealing with this problem is to have a standard by which judgments can be compared. In the use of actual clinical material, three standards can be used: the actual diagnosis of the patient with the benefit of a complete evaluation, the judgments of expert clinicians, and the self-report ratings of the patients. The assumption in using these standards is that the judgments on which they are based are not biased. In the use of hypothetical clinical stimuli, diagnostic criteria should be used to develop the case summaries so that a clear diagnostic standard can be compared to the diagnoses generated by clinician subjects. The judgments of clinical experts can also serve as the standard in studies using hypothetical cases. In any study of clinical judgment bias, efforts should be made to obtain a valid standard by which to assess the nature of any possible judgment bias.

A second important methodological factor is the level of ambiguity in the clinical stimuli. In previous studies, there is some indication that case reports used in the research were either developed to be ambiguous or were selected because of the high level of ambiguity (e.g., Smith, 1974). The assumption underlying this decision is that the effect of the patient's variable on clinical judgments will be most evident when there is a vague case report or initial interview. This assumption may depend on the type of clinical judgment under investigation. For example, studies of diagnostic judgments may require some ambiguity. Otherwise, the diagnoses of case reports clearly meeting the di- agnostic criteria for a specific disorder may not be influenced by a given patient factor, although this was not the case for studies of the mental retardation label. Studies that examine judgments of symptom severity, however, may not benefit from ambiguity in the clinical stimuli. If not enough information is provided so that clinicians can properly identify symptoms or presenting problems, then judgments of symptom severity may more likely represent random judgments that are less likely to be affected by a given patient variable. Particularly for studies of the minimizing bias, it is important that clinicians reliably judge a specific symptom or problem as present. It is only then that the clinician is able to dismiss or minimize the symptom's importance.

A notion related to the level of ambiguity is the amount of information one has in making judgments. In an important nonclinical study, Darley and Gross (1983) found that when raters are given only information about a child's social status (high vs. low social class), they reluctantly judge a child's ability as equal across the two social status conditions. However, when a videotape of the child's performance is presented in conjunction with the background information, raters then apply their stereotype and judge the lower-class child as having less ability than the higher-class child. These results occur in spite of the fact that the actual taped performance did not vary for the two social class levels. Darley and Gross interpreted these findings as indicating that as social judges, people develop hypotheses around information such as social class but do not apply such hypotheses until they believe that there is adequate information to test their hypotheses. The main point of this study is that nonclinicians may interpret the evidence, which is by no means conclusive, as confirming their expectation or stereotype. If this same process occurs among mental health practitioners, written stimuli such as case reports may then be perceived as inadequate evidence for justifying the use of one's stereotypic hypotheses. Stimuli that more closely approximate the actual clinical interview, such as videotaped interviews, may be more likely to capture the selective information processing that may underlie biases of clinical judgment. Therefore, future research may do best in approximating the actual evaluation as much as possible in order to provide the illusion of having adequate evidence.

Not only is it important to approximate the clinical setting in terms of the clinical stimuli, but it may also be important to more closely approximate the interactive nature of clinical judgment over time as opposed to the typical cross-sectional judgment approach. It may prove useful to tap therapists' judgmental processes at two or more points in a given clinical interaction. This may be particularly helpful in assessing when hypotheses are generated and how long they are adhered to in spite of contradictory information. Also, studies of patient variables in clinical judgment may benefit from assessing practitioners' judgments over a period of days, not only to assess hypothesis-testing strategies but also to assess memory processes related to clinical judgment.

Each of the recommendations just outlined is based on the assumption that experimental methods are essential for assessing the effect of patient variables on clinical judgment. This assumption runs counter to the proposed moratorium on analogue studies of clinical judgment bias. The argument used in 
Table 4

Number of Cases of Bias by Analogue and Clinical Studies

\begin{tabular}{|c|c|c|c|c|}
\hline \multirow[b]{2}{*}{ Method } & \multicolumn{2}{|c|}{ Severity judgments } & \multicolumn{2}{|c|}{$\begin{array}{l}\text { Diagnostic } \\
\text { judgments }\end{array}$} \\
\hline & Bias & No bias & Bias & No bias \\
\hline Analogue & 25 & 30 & 15 & 12 \\
\hline Clinical & 7 & 11 & 3 & $\mathbf{0}$ \\
\hline
\end{tabular}

support of the moratorium is that analogue methods are vulnerable to socially desirable responses. S. I. Abramowitz and others have argued that clinicians detect the actual purpose of the study, to assess patient variable biases, and therefore respond in a fashion that does not reflect any such biases. The purported evidence for this position is that analogue studies provide little evidence of bias, whereas clinical studies provide relatively more evidence of bias.

There are two significant problems with this position. First of all, there is no direct evidence that the study manipulations are indeed transparent and in turn lead to nonbiased judgments. In fact, three studies provide evidence that the patient variable manipulation in a between-subjects design is not transparent to most clinician subjects. In a fairly typical study of gender bias, López, Smith, Wolkenstein, and Charlin (1989) instructed 100 subjects to write what they thought the study hypotheses were; only 10 accurately identified the study's intent. In an investigation of age bias, even fewer subjects ( 2 of 44) identified the patient variable manipulation (Wolkenstein \& López, 1988). Lastly, Schover (1981) reported, in an independent study of gender bias and client sexuality, that only 1 of 72 clinician subjects identified the intent of the experimental study. These three studies consistently indicate that $90 \%$ or more of therapists who participate in analogue studies with a between-subjects design are unable to discern the intent of the research.

A second problem with the transparency/social desirability position is that it is based on past reviewers' impressions of the literature and not on systematic examinations of the distribution of bias cases with the two methodologies. The notion that clinical studies are more likely to uncover bias than are analogue studies suggests that the distribution of bias cases will differ for the two research strategies; specifically, clinical studies should have more cases of bias and fewer cases of no bias than analogue studies. To test this assumption, I tabulated the number of cases of bias by research strategy on the basis of the cases identified in Table 1 . Table 4 presents these distributions by judgments of symptom/disorder severity and diagnosis. Chisquare analyses with a Yates correction were conducted for the distributions based on symptom severity, whereas Fisher exact tests were conducted for the distributions based on diagnostic judgments; one of the cells for the latter distributions equaled zero, making the chi-square test less appropriate. The tests reveal that the distribution of bias cases for analogue and clinical research does not significantly differ for cases based on severity judgments, $\left.\chi^{2}(1, N=73)=.05, p>.05\right)$, or on diagnostic judgments $(p=.25)$. To assess whether these findings might be an artifact because of the manner in which a case was defined, I conducted further analyses without the multiple-case studies and without the studies that assessed more than one patient variable effect. Again, the distributions were not found to be significantly different $(p<.05)$. Contrary to the impressions reported in past reviews, these findings are consistent with the hypothesis that analogue research and clinical research do not differ in their ability to uncover bias.

Furthermore, it is important to note that experimental studies are capable of identifying patient variable biases. Considering severity judgments, $45 \%$ of the cases generated by experimental studies uncovered bias in comparison with $39 \%$ of the cases generated by clinical studies. In the study of diagnostic judgments, $55 \%$ of the experimentally based cases provided evidence of bias. The number of clinical cases for diagnostic judgments, however, were too small $(n=3)$ to provide an adequate basis of comparison, although they each demonstrated bias.

In summary, this review indicates that patient variable biases can be identified via experimental methodology. The call for a moratorium on analogue studies does not appear to be appropriate at this time. In fact, the curtailment of experimental studies may serve to impede rather than contribute to the development of this area of research. Instead of foregoing analogue investigations, researchers may do best to take steps to improve past experimental methods, as has been outlined here. The creative use of both experimental and "correlational" methods, in conjunction with a more refined conceptualization, should provide the investigator with the necessary tools to further the study of patient variable biases.

In terms of content, much more research is needed that pertains to all significant patient variable biases. Some groupssuch as Hispanics, Asians, American Indians, the elderly, gay men, and lesbians-are rarely studied or are not studied at all. Perhaps the most glaring omission is the study of the patient's age, particularly in regard to childhood. Although there is clinical evidence of biases against children (Casat, 1982; Weller, Weller, Tucker, \& Fristad, 1986), there are no published studies to my knowledge that have manipulated the patient's age such that the patient is identified as a child/adolescent or as an adult. Another important content area that can benefit from increased attention, particularly from a social cognitive perspective, is the underdiagnosis of physical disorders in mental health patients (Koranyi, 1979; Sternberg, 1986) and the underdiagnosis of mental disorders in health service patients (Kessler, Cleary, \& Burke, 1985).

Consistent with Zeldow (1984), I also recommend that investigators begin to consider errors in judgment that are caused by clinicians' failure to consider important group differences. Past research has examined bias in clinical judgment from the perspective that error occurs when patients of different groups are evaluated differently. As was noted earlier, bias can also occur when patients from two different groups are evaluated in the same manner. For example, clinicians may not consider cultural differences (Adebimpe, 1981; Egeland, Hostetter, \& Eshleman, 1983), developmental norms for children (Garber, 1984) and the elderly (Gatz et al., 1985), gender differences (Seeman, 1986), sexual orientation differences (Gonsiorek, 1982), and differences due to disability, for example, mental retardation (Szymanski \& Biederman, 1984) and hearing impairment (Elliott, Glass, \& Evans, 1987; Misiaszek et al., 1985). This type 
of bias is much more difficult to study because the evidence supporting specific group differences is limited (López \& Núñez, 1987). Clinical investigators will need to familiarize themselves with the available epidemiological and psychopathological literature in order to conduct this research. Nevertheless, studies of this type can make a significant contribution to the bias literature.

As was noted by Zeldow (1978) in one of the first reviews of this area, past research exemplified a shotgun approach. There was little, if any, consideration of the types of errors in clinical judgment, the types of presenting problems, or theoretical perspectives. By considering these factors, future investigators may be able to take better aim at what has been a rather elusive target, that is, patient variable biases in clinical judgment.

\section{References}

Abramowitz, C. V., \& Dokecki, P. R. (1977). The politics of clinical judgment: Early empirical returns. Psychological Bulletin, 84, 460476.

Abramowitz, S. I., Abramowitz, C. V., Jackson, C., \& Gomes, B. (1973). The politics of clinical judgment: What nonliberal examiners infer about women who do not stifle themselves. Journal of Consulting and Clinical Psychology, 41, 385-391.

Abramowitz, S. I., Abramowitz, C. V., Roback, H. B., Corney, R. T., \& McKee, E. (1976). Sex-role related countertransference in psychotherapy. Archives of General Psychiatry, 33, 71-73.

Abramowitz, S. I., \& Herrera, H. R. (1981). On controlling for patient psychopathology in naturalistic studies of sex bias: A methodological demonstration. Journal of Consulting and Clinical Psychology, 49, 597-603.

Abramowitz, S. I., \& Murray, J. (1983). Race effects in psychotherapy. In J. Murray \& P. R. Abramson (Eds.), Bias in psychotherapy (pp. 215-255). New York: Academic Press.

Adebimpe, V. R. (1981). Overview: White norms and psychiatric diagnosis of Black patients. American Journal of Psychiatry, 138, 279285.

Ajzen, I. (1977). Intuitive theories of events and the effects of baserate information on prediction. Journal of Personality and Social Psychology, 35, 303-314.

Alford, J. D., \& Locke, B. J. (1984). Clinical responses to psychopathology of mentally retarded persons. American Journal of Mental Deficiency, 89, 195-197.

American Psychological Association. (1975). Report of the Task Force on Sex Bias and Sex-Role Stereotyping in Psychotherapeutic Practice. American Psychologist, 30, 1169-1175.

Amira, S., Abramowitz, S. I., \& Gomes-Schwartz, B. (1977). Sociallycharged pupil and psychologist effects on psychoeducational decisions. Journal of Special Education, 11, 433-440.

Arkes, H. R. (1981). Impediments to accurate clinical judgment and possible ways to minimize their impact. Journal of Consulting and Clinical Psychology, 49, 323-330.

Arkes, H. R., \& Hammond, K. R. (Eds.). (1986). Judgment and decision making. Cambridge, England: Cambridge University Press.

Arnoult, L. H., \& Anderson, C. A. (1988). Identifying and reducing causal reasoning biases in clinical practice. In D. C. Turk \& P. Salovey (Eds.), Reasoning, inference, and judgment in clinical psychology (pp. 209-232). New York: Free Press.

Bamgbose, O., Edwards, D., \& Johnson, S. (1980). The effects of race and social class on clinical judgment. Journal of Clinical Psychology, 36, 605-609.

Bar-Hillel, M. (1980). The base-rate fallacy in probability judgments. Acta Psychologica, 44, 211-233.
Benefee, L. M., Abramowitz, S. I., Weitz, L. J., \& Armstrong, S. H. (1976). Effects of patient racial attribution on Black clinicians' inferences. American Journal of Community Psychology, 4, 263-273.

Benson, P. R. (1983). Factors associated with antipsychotic drug prescribing by Southern psychiatrists. Medical Care, 21, 639-654.

Bernard, R., \& Clarizio, H. (1982). Socioeconomic bias in special education placement decisions. Psychology in the Schools, 18, 178-183.

Bernstein, B., \& Kane, R. (1981). Physicians' attitudes toward female patients. Medical Care, 19, 600-608.

Bernstein, B. L., \& LeComte, C. (1982). Therapist expectancies: Client gender and therapist gender, profession, and level of training. Journal of Clinical Psychology, 38, 744-754.

Biener, L. (1983). Perceptions of patients by emergency room staff: Substance-abusers versus non-substance-abusers. Journal of Health and Social Behavior, 24, 264-275.

Billingsley, D. (1977). Sex bias in psychotherapy: An examination of the effects of client sex, client pathology, and therapist sex on treatment planning. Journal of Consulting and Clinical Psychology, 45, 250256.

Blake, W. (1973). The influence of race on diagnosis. Smith College Studies in Social Work, 43, 184-192.

Blane, H. T., Overton, W. F., Jr., \& Chafetz, M. E. (1963). Social factors in the diagnosis of alcoholism: I. Characteristics of the patient. Quarterly Journal of Studies on Alcohol, 24, 640-663.

Bloch, P. M., Weitz, L. J., \& Abramowitz, S. I. (1980). Racial attribution effects on clinical judgment: A failure to replicate among White clinicians. American Journal of Community Psychology, 8, 484-493.

Bodenhausen, G. V., \& Lichtenstein, M. (1987). Social stereotypes and information-processing strategies: The impact of task complexity. Journal of Personality and Social Psychology, 52, 871-880.

Borgida, E., \& Nisbett, R. (1977). The differential impact of abstract vs. concrete information on decisions. Journal of Applied Social Psychology, 7, 258-271.

Bowman, P. R. (1982). An analog study with beginning therapists suggesting bias against "activity" in women. Psychotherapy: Theory, Research and Practice, 19, 318-324.

Buczek, T. A. (1981). Sex biases in counseling: Counselor retention of the concerns of a female and male client. Journal of Counseling Psychology, 28, 13-21.

Casas, J. M., Brady, S., \& Ponterotto, J. G. (1983). Sexual preference biases in counseling: An information processing approach. Journal of Counseling Psychology, 30, 139-145.

Casat, C. D. (1982). The under- and over-diagnosis of mania in children and adolescents. Comprehensive Psychiatry, 23, 552-559.

Chapman, L. J., \& Chapman, J. P. (1969). Illusory correlation as an obstacle to the use of valid psychodiagnostic signs. Journal of Abnormal Psychology, 14, 271-280.

Chess, S., Clark, K. B., \& Thomas, A. (1953). The importance of cultural evaluation in psychiatric diagnosis and treatment. Psychiatric Quarterly, 27, 102-114.

Christensen-Szalanski, J. J. J., \& Beach, L. R. (1982). Experience and base rate fallacy. Organizational Behavior and Human Performance, 29, 270-278.

Clarizio, H. F., \& Phillips, S. E. (1986). Sex bias in the diagnosis of learning disabled students. Psychology in the Schools, 25, 44-52.

Coie, J. D., Pennington, B. F., \& Buckley, H. H. (1974). Effects of situational stress and sex roles on the attribution of psychological disorder. Journal of Consulting and Clinical Psychology, 42, 559-568.

Cronkite, R. C., \& Moos, R. H. (1984). Sex and marital status in relation to the treatment and outcome of alcoholic patients. Sex Roles, $11,93-112$.

Dailey, D. M. (1980). Are social workers sexist? A replication. Social Work, 25, 46-50.

Darley, J. M., \& Gross, P. H. (1983). A hypothesis-confirming bias in 
labeling effects. Journal of Personality and Social Psychology, 44, 2033.

Davidson, C. V., \& Abramowitz, S. E. (1980). Sex bias in clinical judgment: Later empirical returns. Psychology of Women Quarterly, 4, 377-395.

Deaux, K. (1976). Sex: A perspective on the attribution process. In J. H. Harvey, W. J. Ickes, \& R. F. Kidd (Eds.), New directions in attribution research (Vol. 1, pp. 335-352). Hillsdale, NJ: Erlbaum.

Del Gaudio, A. C., Carpenter, P. J., \& Morrow, G. R. (1978). Male and female treatment differences: Can they be generalized? Journal of Consulting and Clinical Psychology, 46, 1577-1578.

Derogatis, L. R., Covi, L., Lipman, R. S., Davis, D. M., \& Rickels, K. (1971). Social class and race as mediator variables in neurotic symptomatology. Archives of General Psychiatry, 25, 31-40.

DiNardo, P. A. (1975). Social class and diagnostic suggestion as variables in clinical judgment. Journal of Consulting and Clinical Psychology, 43, 363-368.

Duncan, B. L. (1976). Differential social perception and attribution of intergroup violence: Testing the lower limits of stereotyping of Blacks. Journal of Personality and Social Psychology, 34, 590-598.

Egeland, J. A., Hostetter, A. M., \& Eshleman, S. K. III. (1983). Amish study: III. The impact of cultural factors on diagnosis of bipolar illness. American Journal of Psychiatry, 140, 67-71.

Einhorn, H. J., \& Hogarth, R. M. (1981). Behavioral decision theory: Processes of judgment and choice. Annual Review of Psychology, 32, 53-88.

Elk, R., Dickman, B. J., \& Teggin, A. F. (1986). Depression in schizophrenia: A study of prevalence and treatment. British Journal of Psychiatry, 149, 228-229.

Elliott, H., Glass, L., \& Evans, J. W. (1987). Mental health assessment of deaf clients: A practical manual. Boston: College-Hill.

Elstein, A. S., Shulman, L. S., \& Sprafka, S. A. (1978). Medical problem solving: An analysis of clinical reasoning. Cambridge, MA: Harvard University Press.

Feinblatt, J. A., \& Gold, A. R. (1976). Sex roles and the psychiatric referral process. Sex Roles, 2, 109-122.

Fischer, J., Dulaney, D. D., Fazio, R. T., Hudak, M. T., \& Zivotofsky, E. (1976). Are social workers sexists? Social Work, 21, 428-433.

Fiske, S. T., \& Taylor, S. E. (1984). Social cognition. Reading, MA: Addison-Wesley.

Fleiss, J. F. (1981). Statistical methods for rates and proportions (2nd ed.). New York: Wiley.

Ford, C. V., \& Sbordone, R. J. (1980). Attitudes of psychiatrists toward elderly patients. American Journal of Psychiatry, 137. 571-575.

Frame, R. E., Clarizio, H. F., Porter, A., \& Vinsonhaler, J. R. (1982). Interclinician agreement and bias in school psychologists' diagnostic and treatment recommendations for a learning disabled child. $P s y-$ chology in the Schools, 19, 319-327.

Franklin, D. L. (1985). Differential clinical assessments: The influence of class and race. Social Service Review, 59, 44-61.

Garber, J. (1984). Classification of childhood psychopathology: A developmental perspective. Child Development, 55, 30-48.

Gatz, M., Popkin, S. J., Pino, C. D., \& VandenBos, G. R. (1985). Psychological interventions with older adults. In J. Birren \& K. W. Schaie (Eds.), Handbook of the psychology of aging (pp. 755-785). New York: Van Nostrand Reinhold.

Ginossar, Z., \& Trope, Y. (1987). Problem solving in judgment under uncertainty. Journal of Personality and Social Psychology, 52, 464474.

Ginsberg, S. M., \& Brown, G. W. (1982). No time for depression: A study of help-seeking among mothers of preschool children. In D. Mechanic (Ed.), Symptoms, illness behavior, and help-seeking (pp. 87-114). New York: Prodist.
Gonsiorek, J. C. (1982). The use of diagnostic concepts in working with gay and lesbian populations. Journal of Homosexuality, 7, 9-20.

Haase, W. (1964). Role of socioeconomic class in examiner bias. In F. Reissman, J. Cohen, \& A. Pearl (Eds.), Mental health of the poor (pp. 241-247). New York: Free Press.

Hamilton, D. L. (1981). Illusory correlations as a basis of stereotyping. In D. L. Hamilton (Ed.), Cognitive processes in stereotyping and intergroup behavior (pp. 115-144). Hillsdale, NJ: Erlbaum.

Hamilton, D. L., Dugan, P., \& Trolier, T. (1985). The formation of stereotypic beliefs: Further evidence for distinctiveness-based illusory correlation. Journal of Personality and Social Psychology, 48, 5-17.

Hare-Mustin, R. T. (1983). An appraisal of the relationship between women and psychotherapy: 80 years after the case of Dora. American Psychologist, 38, 593-601.

Hastie, R. (1981). Schematic principles in human memory. In E. T. Higgins, C. P. Herman, \& M. P. Zanna (Eds.), Social cognition: The Ontario Symposium (pp. 39-88). Hillsdale, NJ: Erlbaum.

Hastie, R., \& Kumar, P. A. (1979). Person memory: Personality traits as organizing principles in memory for behaviors. Journal of Personality and Social Psychology, 37, 25-38.

Hemsley, G. D., \& Marmurek, H. H. C. (1982). Person memory: The processing of consistent and inconsistent person information. Personality and Social Psychology Bulletin, 8, 433-438.

Higgins, E. T., \& Bargh, J. A. (1987). Social cognition and social perception. Annual Review of Psychology, 38, 369-425.

Horwitz, A. V., \& White, H. R. (1987). Gender role orientations and styles of pathology among adolescents. Journal of Health and Human Behavior, 28, 158-170.

Houts, A. C., \& Graham, K. (1986). Can religion make you crazy? Impact of client and therapist religious values on clinical judgments. Journal of Consulting and Clinical Psychology, 54, 267-271.

Huebner, E. S., \& Cummings, J. A. (1985). The impact of sociocultural background and assessment data upon school psychologists' decisions. Journal of School Psychology, 23, 157-166.

Kahneman, D., Slovic, P., \& Tversky, A. (Eds.), (1982). Judgment under uncertainty: Heuristics and biases. Cambridge, England: Cambridge University Press.

Kahneman, D., \& Tversky, A. (1973). On the psychology of prediction. Psychological Review, 80, 237-251.

Kassirer, J. P., \& Gorry, G. A. (1978). Clinical problem solving: A behavioral analysis. Annals of Internal Medicine, 89, 245-255.

Kessler, L. G., Cleary, P. D., \& Burke, J. D. (1985). Psychiatric disorders in primary care: Results of a follow-up study. Archives of General Psychiatry, 42, 583-587.

Kirshner, L. A., \& Johnston, L. (1983). Effects of gender on inpatient psychiatric hospitalization. Journal of Nervous and Mental Disease, 171, 651-657.

Koranyi, E. K. (1979). Morbidity and rate of undiagnosed physical illnesses in a psychiatric clinic population. Archives of General Psychiatry, 36, 414-419.

Koscherak, S., \& Masling, J. (1972). Noblesse oblige effect: The interpretation of Rorschach responses as a function of ascribed social class. Journal of Consulting and Clinical Psychology, 39, 415-419.

Lee, S. D., \& Temerlin, M. K. (1970). Social class, diagnosis, and prognosis for psychotherapy. Psychotherapy: Theory, Research and Practice, 7, 181-185.

Leinhardt, G., Seewald, A. M., \& Zigmond, N. (1982). Sex and race differences in learning disabilities classrooms. Journal of Educational Psychology, 74, 835-843.

Levy, M., \& Kahn, M. (1970). Interpreter bias on the Rorschach test as a function of patients' socioeconomic status. Journal of Projective Techniques and Personality Assessment, 34; 106-112.

Lewis, K. N., \& Lewis, D. A. (1985). Impact of religious affiliation on 
therapists' judgments of patients. Journal of Consulting and Clinical Psychology, 53, 926-932.

Locksley, A., Borgida, E., Brekke, N., \& Hepburn, C. (1980). Sex stereotypes and social judgment. Journal of Personality and Social Psychology, 39, 821-831.

López, S. (1983a). Ethnic bias in clinical judgment: An attributional analysis. Unpublished doctoral dissertation, University of California, Los Angeles.

López, S. (1983b). The study of psychotherapy bias: Some conceptual issues and some concluding comments. In J. Murray \& P. R. Abramson (Eds.), Bias in psychotherapy (pp. 353-365). New York: Praeger.

López, S., \& Hernandez, P. (1986). How culture is considered in evaluations of psychopathology. Journal of Nervous and Mental Disease, 174, 598-606.

López, S., \& Núñez, J. A. (1987). The consideration of cultural factors in selected diagnostic criteria and interview schedules. Journal of $A b$ normal Psychology, 96, 270-272.

López, S. R., Smith, A., Wolkenstein, B. H., \& Charlin, V. (1989). Gender bias in clinical judgment: An assessment of the analogue method's transparency and social desirability. Manuscript submitted for publication.

Lowery, C. R., \& Higgins, R. L. (1979). Analogue investigation of the relationship between clients' sex and treatment recommendations. Journal of Consulting and Clinical Psychology, 47, 792-794.

Luepnitz, R. R., Randolph, D. L., \& Gutsch, K. U. (1982). Race and socioeconomic status as confounding variables in the accurate diagnosis of alcoholism. Journal of Clinical Psychology, 38, 665-669.

Martin, C. L. (1987). A ratio measure of sex stereotyping. Journal of Personality and Social Psychology, 52, 489-499.

Matuszek, P., \& Oakland, T. (1979). Factors influencing teachers' and psychologists' recommendations regarding special class placement. Journal of School Psychology, 17, 116-125.

McCauley, C., Stitt, C. L., \& Segal, M. (1980). Stereotyping: From prejudice to prediction. Psychological Bulletin, 87, 195-208.

McIntosh, J. L. (1985). Suicide among the elderly: Levels and trends. American Journal of Orthopsychiatry, 55, 288-293.

McLaughlin, M., \& Balch, P. (1980). Effects of client-therapist ethnic homophily on therapists' judgments. American Journal of Community Psychology, 8, 243-252.

Merluzzi, B. H., \& Merluzzi, T. V. (1978). Influences of client race on counselors' assessment of case materials. Journal of Counseling Psychology, 25, 399-404.

Misiaszek, J., Dooling, J., Gieseke, M., Melman, H., Misiaszek, J. G., \& Jorgensen, K. (1985). Diagnostic considerations in deaf patients. Comprehensive Psychiatry, 26, 513-521.

Mukherjee, S., Shukla, S., Woodle, J., Rosen, A. M., \& Olarte, S. (1983). Misdiagnosis of schizophrenia in bipolar patients: A multiethnic comparison. American Journal of Psychiatry, 140, 1571-1574.

Murray, J., \& Abramson, P. R. (1983). An investigation of the effects of client gender and attractiveness on psychotherapists' judgments. In J. Murray \& P. R. Abramson (Eds.), Bias in psychotherapy (pp. 129167). Los Angeles: University of California Press.

Mynatt, C. R., Doherty, M. E., \& Tweney, R. D. (1978). Consequences of confirmation and disconfirmation in a simulated research environment. Quarterly Journal of Experimental Psychology, 30, 395-406.

Neer, W. L., Foster, D. A., Jones, J. G., \& Reynolds, D. A. (1973). Socioeconomic bias in the diagnosis of mental retardation. Exceptional Children, 40, 38-39.

Nisbett, R. E., \& Borgida, E. (1975). Attribution and the psychology of prediction. Journal of Personality and Social Psychology, 32, 932943.

Norman, R. D., \& Martinez, R. (1978). Social class and ethnicity effects on clinical judgments. Psychological Reports, 43, 91-98.

Oyster-Nelson, C. K., \& Cohen, L. H. (1981). The extent of sex bias in clinical treatment recommendations. Professional Psychology, 12, 508-515.

Park, B., \& Rothbart, M. (1982). Perception of out-group homogeneity and levels of social categorization: Memory for the subordinate attributes of in-group and out-group members. Journal of Personality and Social Psychology, 42, 1051-1068.

Perlick, D., \& Atkins, A. (1984). Variations in the reported age of a patient: A source of bias in the diagnosis of depression and dementia. Journal of Consulting and Clinical Psychology, 52, 812-820.

Pfeiffer, E. (1977). Psychopathology and social pathology. In J. E. Birren \& K. W. Schaie (Eds.), Handbook of psychology of aging (pp. 650671). New York: Van Nostrand Reinhold.

Polister, P. (1981). Decision analysis and clinical judgment: A re-evaluation. Medical Decision Making, 1, 361-389.

Popkin, M. K., Mackenzie, T. B., \& Callies, A. L. (1984). Psychiatric consultation to geriatric medically ill inpatients in a university hospital. Archives of General Psychiatry, 41, 703-707.

Raskin, A., Crook, T. H., \& Herman, K. D. (1975). Psychiatric history and symptom differences in black and white depressed inpatients. Journal of Consulting and Clinical Psychology, 43, 73-80.

Reiss, S., Levitan, G. W., \& Szyszko, J. (1982). Emotional disturbance and mental retardation: Diagnostic overshadowing. American Journal of Mental Deficiency, 86, 567-574.

Reiss, S., \& Szyszko, J. (1983). Diagnostic overshadowing and professional experience with mentally retarded persons. American Journal of Mental Deficiency, 87, 396-402.

Rosenfield, S. (1982). Sex roles and societal reactions to mental illness: The labeling of "deviant" deviance. Journal of Health and Social Behavior, 23, 18-23.

Rosenfield, S. (1984). Race differences in involuntary hospitalization: Psychiatric vs. labeling perspective. Journal of Health and Social Behavior, 25, 14-23.

Rothbart, M. (1981). Memory processes and social beliefs. In D. L. Hamilton (Ed.), Cognitive processes in stereotyping and intergroup behavior (pp. 145-182). Hillsdale, NJ: Erlbaum.

Routh, D. K., \& King, K. M. (1972). Social class bias in clinical judgment. Journal of Consulting and Clinical Psychology, 38, 202-207.

Schover, L. R. (1981). Male and female therapists' responses to male and female client sexual material: An analogue study. Archives of Sexual Behavior, 10, 477-492.

Schwartz, J. M., \& Abramowitz, S. I. (1975). Value-related effects on psychiatric judgment. Archives of General Psychiatry, 32, $1525-1529$.

Seeman, M. V. (1986). Current outcome in schizophrenia: Women vs men. Acta Psychiatrica Scandinavica, 73, 609-617.

Settin, J. M. (1982). Clinical judgment in geropsychology practice. Psychotherapy: Theory, Research and Practice, 19, 397-404.

Severance, L., \& Gasstrom, L. (1977). Effects of the label "mentally retarded" on causal explanations for success and failure outcomes. American Journal of Mental Deficiency, 81, 547-555.

Simon, R. J., Fleiss, J. L., Gurland, B. J., Stiller, P. R., \& Sharpe, L. (1973). Depression and schizophrenia in hospitalized Black and White mental patients. Archives of General Psychiatry, 28, 509-512.

Smith, M. L. (1974): Influence of client sex and ethnic group on counselor judgments. Journal of Counseling Psychology, 21, 516-521.

Smith, M. L. (1980). Sex bias in counseling and psychotherapy. Psychological Bulletin, 87, 392-407.

Snyder, M., \& Swann, W. B., Jr. (1978). Behavioral confirmation in social interaction: From social perception to social reality. Journal of Experimental Social Psychology, 14, 148-162.

Snyder, M., \& Thomsen, C. J. (1988). Interactions between therapists and clients: Hypothesis testing and behavioral confirmation. In D. C. Turk \& P. Salovey (Eds.), Reasoning, inference, and judgment in clinical psychology (pp. 124-152). New York: Free Press.

Stack, L. C., Lannon, P. B., \& Miley, A. D. (1983). Accuracy of clini- 
cians' expectancies for psychiatric rehospitalization. American Journal of Community Psychology, 11, 99-113.

Stearns, B. C., Penner,L. A., \& Kimmel, E. (1980). Sexism among psychotherapists: A case not yet proven. Journal of Consulting and Clinical Psychology, 48, 548-550.

Stein, L. S., Del Gaudio, A. C., \& Ansley, M. Y. (1976). A comparison of female and male neurotic depressives. Journal of Clinical Psychology, 32, 19-21.

Sternberg, D. E. (1986). Testing for physical illness in psychiatric patients. Journal of Clinical Psychiatry, 47(1,Suppl.), 3-9.

Stevens, G. (1981). Bias in the attribution of hyperkinetic behavior as a function of ethnic identification and socioeconomic status. Psychology in the Schools, 18, 99-106.

Sutton, R. G., \& Kessler, M. (1986). National study of the effects of clients' socioeconomic status on clinical psychologists' professional judgments. Journal of Consulting and Clinical Psychology, 54, 275276.

Szymanski, L. S., \& Biederman, J. (1984). Depression and anorexia nervosa of persons with Down syndrome. American Journal of Mental Deficiency, 89, 246-251.

Task Force on Sex Bias and Sex-Role Stereotyping in Psychotherapeutic Practice. (1978). Guidelines for therapy with women. American Psychologist, 33, 1122-1123.

Taylor, D. M., \& Jaggi, V. (1974). Ethnocentrism and causal attribution in a South Indian context. Journal of Cross Cultural Psychology, 5, $162-171$.

Teri, L. (1982). Effects of sex and sex-role style on clinical judgment. Sex Roles, 8, 639-649.

Trachtman, J. P. (1971). Socio-economic class bias in Rorschach diagnosis: Contributing psychological attributes of the clinician. Journal of Projective Techniques and Personality Assessment, 35, 229-240.

Tucker, J. A. (1980). Ethnic proportions in classes for the learning disabled: Issues in nonbiased assessment. Journal of Special Education, 14, 93-105.

Turk, D. C., \& Salovey, P. (1986). Clinical information processing: Bias inoculation. In R. E. Ingram (Ed.), Information processing approaches to clinical psychology (pp. 305-323). Orlando, Fl: Academic Press.

Turk, D. C., \& Salovey, P. (1988). Psychotherapy: An information-processing perspective. In D. C. Turk \& P. Salovey (Eds.), Reasoning, inference, and judgment in clinical psychology (pp. 1-14). New York: Free Press.

Tversky, A., \& Kahneman, A. (1980). Causal schemata in judgments under uncertainty. In M. Fishbein (Ed.), Progress in social psychology (pp. 49-72). Hillsdale, NJ: Erlbaum.

Umbenhauer, S. L., \& DeWitte, L. L. (1978). Patient race and social class: Attitudes and decisions among three groups of mental health professionals. Comprehensive Psychiatry, 19, 509-515.

Verbugge, L. M. (1984). How physicians treat mentally distressed men and women. Social Science and Medicine, 18, 1-9.

Wadsworth, R. D., \& Checketts, K. T. (1980). Influence of religious affiliation on psychodiagnosis. Journal of Consulting and Clinical Psychology, 48, 234-246.
Wallsten, T. S. (1981). Physician and medical student bias in evaluating diagnostic information. Medical Decision Making, 1, 145-164.

Wampold, B. E., Casas, J. M., \& Atkinson, D. R. (1981). Ethnic bias in counseling: An information processing approach. Journal of Counseling Psychology, 28, 498-503.

Warner, R. (1978). The diagnosis of antisocial and hysterical personality disorders: An example of sex bias. Journal of Nervous and Mental Disease, 166, 839-845.

Warner, R. (1979). Racial and sexual bias in psychiatric diagnosis. Journal of Nervous and Mental Disease, 167, 303-310.

Weiner, B. (1985). An attributional theory of achievement motivation and emotion.' Psychological Review, 92, 548-573.

Weiner, B. (1986). An attributional theory of motivation and emotion. New York: Springer-Verlag.

Weissman, M. M., \& Klerman, G. L. (1977). Sex differences and the epidemiology of depression. Archives of General Psychiatry, 34, 98111.

Weisz, J. R. (1981). Effects of the "mentally retarded" label on adult judgments about child failure. Journal of Abnormal Psychology, 90 , 371-374.

Weller, R. A., Weller, E. B., Tucker, S. G., \& Fristad, M. A. (1986). Mania in prepubertal children: Has it been underdiagnosed? Journal of Affective Disorders, 11, 151-154.

Wolf, I., Chafetz, M. E., Blane, H. T., \& Hill, M. J. (1965). Social factors in the diagnosis of alcoholism: II. Attitudes of physicians. Quarterly Journal of the Study of Alcoholism, 26, 72-79.

Wolkenstein, B. H., \& López, S. (1988, August). Underlying social cognitive processes of age bias in clinical judgment. Paper presented at the annual meeting of the American Psychological Association, Atlanta.

Yamamoto, J., James, Q. C., Bloombaum, M., \& Hattem, J. (1967). Racial factors in patient selection. American Journal of Psychiatry, $124,630-636$.

Yarkin, K. L., Town, J. P., \& Wallston, B. S. (1982). Blacks and women must try harder: Stimulus persons' race and sex attributions of causality. Personality and Social Psychology Bulletin, 8, 21-24.

Young, L. M., \& Powell, B. (1985). The effects of obesity on the clinical judgments of mental health professionals. Journal of Health and Social Behavior, 26, 233-246.

Zeldow, P. B. (1978). Sex differences in psychiatric evaluation and treatment. Archives of General Psychiatry, 35, 89-93.

Zeldow, P. B. (1984). Sex roles, psychological assessment, and patient management. In C. S. Widom (Ed.), Sex roles and psychopathology (pp. 355-374). New York: Plenum.

Zukier, H., \& Pepitone, A. (1984). Social roles and strategies in prediction: Some determinants of the use of base-rate information. Journal of Personality and Social Psychology, 47, 349-360.

Received June 9, 1988

Revision received November 28, 1988 Accepted November 28, 1988 